\title{
An Integrated Extreme Rainfall Modeling Tool (SDExtreme) for Climate Change Impacts and Adaptation
}

Myeong-Ho Yeo ( $\nabla$ yeom@triton.uog.edu )

University of Guam https://orcid.org/0000-0002-6488-5309

Van-Thanh-Van Nguyen

McGill University

Yong Sang Kim

University of Guam

Theodore A. Kpodonu

Auckland Council

\section{Research Article}

Keywords: extreme rainfalls, intensity-duration-frequency relations, statistical downscaling, generalized extreme value distribution, confidence interval of IDF curves, climate change impacts

Posted Date: May 17th, 2021

DOI: https://doi.org/10.21203/rs.3.rs-338969/v1

License: (c) (i) This work is licensed under a Creative Commons Attribution 4.0 International License. Read Full License 


\section{Change Impacts and Adaptation}

3 Myeong-Ho Yeo ${ }^{1 *}$, Van-Thanh-Van Nguyen ${ }^{2}$, Yong Sang Kim ${ }^{1}$, and Theodore A. Kpodonu ${ }^{3}$

$4{ }^{1}$ Water and Environmental Research Institute of the Western Pacific, University of Guam,

5 Mangilao, GU 96923, USA

$6 \quad 2$ McGill University, Department of Civil Engineering and Applied Mechanics, 817 Sherbrooke

7 Street West, Montreal, Quebec, Canada

$8 \quad{ }^{3}$ Auckland Council, Health Waters, Infrastructure \& Environmental Services, Level 3, Bledisloe

9 House, 24 Wellesley Street, Auckland, New Zealand

10

11 Corresponding author: Myeong-Ho Yeo

12 Corresponding author's email: yeom@triton.uog.edu

13 Corresponding author's address: Water and Environmental Research Institute of the Western

14 Pacific, 303 University Drive, University of Guam, Mangilao, GU 96923, USA

15 Corresponding author's Tel.: 671-735-2693

16 ORCID Id: 0000-0002-6488-5309

17 


\section{Abstract}

19 The estimation of the Intensity-Duration-Frequency (IDF) relations is often necessary for the

20 planning and design of various hydraulic structures and design storms. It has been an increasingly

21 greater challenge due to climate change condition. This paper therefore proposes an integrated

22 extreme rainfall modeling software package (SDExtreme) for constructing the IDF relations at a

23 local site in the context of climate change. The proposed tool is based on a temporal downscaling

24 method to describe the relationships between daily and sub-daily extreme precipitation using the

25 scale-invariance General Extreme Value (GEV) distribution. In addition, SDExtreme provides a

26 modified bootstrap technique to determine confidence intervals (CIs) of the estimated IDF curves

27 for the current and the future climate conditions. The feasibility and accuracy of SDExtreme were

28 assessed using rainfall data available from the selected rain gauge stations in Quebec and Ontario

29 provinces (Canada) and climate simulations under three different climate change scenarios

30 provided by the Canadian Earth System Model (CanESM2) and the Canadian Regional Climate

31 Model (CanRCM4).

33 Keywords: extreme rainfalls; intensity-duration-frequency relations; statistical downscaling;

34 generalized extreme value distribution; confidence interval of IDF curves; climate change impacts 


\section{Introduction}

In urban hydrology and drainage applications, the rainfall intensity-duration frequency (IDF) relation for a given site is always required for the design and management of stormwater works. For locations where observed annual maximum precipitations (AMPs) are available, frequency analysis is implemented to estimate design rainfall intensities for a specific duration and

41 a given return period (Buishand, 1989, Wilks, 1993, Zalina et al., 2002). The computational

42 procedure of constructing the IDF relation can be summarized as: i) select the appropriate 43 distribution, ii) parameterize the selected distribution for each duration, and iii) estimate quantiles

44 (or intensities) with respect to the desired return periods. spatial scale limitation, and climate change condition. The inferences from this procedure are

47 applicable only to the particular time scale associated with the data used and at a local site where 48 data are available. Satellite, Weather Research and Forecasting (WRF) model, and some statistical 49 techniques are proposed to overcome the spatial scale limitation (Pizarro et al., 2018, Liew et al., 50 2014, Ombadi et al., 2018, Ouali and Cannon, 2018). Efforts to describe the association of extreme 51 rainfalls at different time scales have been proposed and tested (Gupta and Waymire, 1990, 52 Nguyen et al., 2002, Nhat et al., 2007, Vu et al., 2018, Yeo et al., 2020), however, it is unable to 53 investigate climate change impacts on extreme rainfalls in the future time. By coupling climate 54 change scenarios and the described temporal association, the IDF curves have been updated to 55 account for the climate change impacts on extreme rainfalls and flooding (Nguyen et al., 2008, Vu 56 et al., 2018, Yeo, 2014).

More specifically, it has been recognized that society becomes more vulnerable to extreme weather and climate events. Continuing population growth, land use changes, and industrial 
59 development will further increase vulnerability by creating more potential for catastrophic impacts

60 from climate extremes such as severe flooding events with large loss of human life, excessive

61 economic losses, and uncertain long-term consequences to ecosystems. Of particular interest for

62 water management are the investigations of precipitation change that have revealed some empirical

63 evidence of increasing trends in precipitation extremes over many regions of the world (IPCC,

64 2014). Hence, it is important to understand not only the current patterns of extreme rainfalls but

65 also how they are likely to change in the future. General Circulation Models (GCMs) have been

66 recognized to be able to represent the main features of the global distribution of some basic climate

67 parameters. Outputs from these models, however, are not usually applicable for frequency analysis

68 at a local site due to their coarse temporal resolutions. To incorporate the climate change conditions

69 into frequency analyses, the scale invariance properties of AMPs are coupled to GCMs' outputs

70 (Nguyen et al., 2008, Vu et al., 2018, Yeo et al., 2020).

71 Confidence intervals (CIs) have been used to indicate the uncertainty of quantiles in

72 hydrological frequency analysis. The uncertainty in extreme rainfall event estimation is the result

73 of insufficient data size, the procedure for selecting appropriate probability distribution, and the

74 estimation of parameters of the selected distribution. The increasing trend in the maximum daily

75 and sub-daily rainfalls intensities becomes a critical challenge in the construction of future IDF

76 curves. The use of ensemble of multiple climate change models and the downscaling approaches

77 have been suggested to represent the uncertainty. However, it also has the additional challenge to

78 determine appropriate climate models for extreme rainfall events because the extreme values

79 behave differently (Yeo et al., 2020).

This paper introduces a software package that enables the construction of IDF curves and

81 their CIs for the present and the future if a user has the historical annual maximum precipitation 
82 series and daily climate change scenarios' outputs. There are already well-known commercial/non-

83 profit tools such as Hydrognomon (Kozanis et al., 2010), HydroCAD (HydroCAD Software

84 Solutions, 2015), TechnoLogismiki Works, and IDF_CC tool (Simonovic et al., 2016). These tools,

85 however, are unable to account for the temporal scale limitations and climate change issue except

86 IDF_CC tool. Moreover, these tools do not provide the users with the CI for the future IDF curves.

87 Hence, the proposed IDF estimation tool, whose name is Statistical Downscaling for Extreme

88 Rainfall (SDExtreme) available at the Mendeley Dataset

89 (https://data.mendeley.com/datasets/kc9frpgfvs/1), can be used to estimate the IDF curves and the

90 CIs for current and future periods. The dataset includes an installation file for SDExtreme and two

91 example files from the three selected rain gauge stations from Ontario and Quebec Provinces

92 (Canada). Because the main source codes are compiled by MATLAB 2014a, the requirement for

93 running this software is to install MATLAB Runtime version 8.3 (see the website:

94 https://www.mathworks.com/products/compiler/matlab-runtime.html).

95 In this study, the proposed assessment tool is tested using a historical annual maximum

96 precipitation series available for the period of 1961-1990 from sixteen rain gauge networks located

97 in Southern Ontario and Quebec Provinces (Canada). As for the effects of climate change on

98 extreme rainfall system, future weather conditions are projected using the same set of variables

99 taken from three climate change scenarios (RCP 2.6, RCP 4.5, and RCP 8.5) given by the second-

100 generation Canadian Earth System Model (CanESM2) and two climate change scenarios (RCP 4.5

101 and RCP 8.5) by the Canadian Regional Climate Model (CanRCM4). The proposed tool is used to

102 generate future IDF curves and CI associated with both CanESM2 and CanRCM4 climate change

103 scenarios. 
105 the theoretical approach, section 3 describes the design and application, and the last section present 106 our conclusion, respectively.

\section{2. Model Developments}

In this section, we review the three steps, which are described in more detail in Yeo et al.

110 (2020) and Nguyen et al. (2008).

\subsection{Temporal Downscaling using Scaling- General Extreme Value (GEV) distribution}

113 rainfalls for different durations and to construct the IDF curves (Nguyen et al., 2008, Yeo et al.,

114 2020). The cumulative distribution function, $F(x)$, for the GEV distribution is given as

$$
F(x)=\exp \left[-\left(1-\frac{\kappa(x-\xi)}{\alpha}\right)^{1 / \kappa}\right] \quad(\kappa \neq 0)
$$

115 where $\xi, \alpha$, and $\kappa$ are the location, scale, and shape parameter, respectively. The $k$-th order of non116 central moments (NCMs), $\mu_{k}$, of the GEV distribution can be expressed as:

$$
\mu_{\kappa}=\left(\xi+\frac{\alpha}{\kappa}\right)^{k}+(-1)^{k}\left(\frac{\alpha}{\kappa}\right)^{k} \Gamma(1+k \kappa)+k \sum_{i=1}^{k-1}(-1)^{i}\left(\frac{\alpha}{\kappa}\right)^{i}\left(\xi+\frac{\alpha}{\kappa}\right)^{k-i} \Gamma(1+i \kappa)
$$

117 in which $\Gamma(\cdot)$ is the gamma function. Therefore, it is possible to estimate parameters $(\xi, \alpha$, and $\kappa)$

118 of GEV distribution by the method of moments (MOM) using the first three NCMs. The quantiles $119\left(X_{\tau}\right)$ can be calculated by the inverse distribution function as follows: 


$$
X_{\tau}=\xi+\frac{\alpha}{\kappa}\left\{1-[-\ln (p)]^{k}\right\}
$$

120 where $p$ is the exceedance probability of interest and $\tau$ is the return period.

121 For a simple scaling process, the relationship between the NCMs of order $k$ and the

122 variable $t$ can be written in a general form as follows:

$$
\mu_{k}=E\left\{f^{k}(t)\right\}=t^{\beta(k)} a(k)
$$

123 in which $\alpha(k)=\left\{f^{k}(1)\right\}$ and $\beta(k)=k \beta$ under simple scaling condition. Hence, the scaling

124 behavior of extreme rainfall can be examined by the power-form relationship between the $k$-order

$125 \mathrm{NCMs}$ and the $\mathrm{t}$ durations. If extreme rainfall data exhibit the scaling properties, the log-linearity 126 will be shown.

129 related as follows:

$$
\begin{aligned}
& \kappa(\lambda t)=\kappa(t) \\
& \alpha(\lambda t)=\lambda^{\beta} \alpha(t) \\
& \xi(\lambda t)=\lambda^{\beta} \xi(t) \\
& X_{T}(\lambda t)=\lambda^{\beta} X_{T}(t)
\end{aligned}
$$

130 Based on these relationships, it is possible to derive the statistical properties of sub-daily AMPs 131 using the properties of daily AMPs. Therefore, the proposed GEV distribution based on the scaling 
132 property of NCMs for different rainfall durations can be used to construct the IDF curves for a 133 given site.

134 Yeo at al. (2020) addresses three possible parameter estimation methods (Scaling L135 moment, Scaling One-NCM, and Scaling Three-NCM) from Equation 4 8. The comparison 136 studies with observed AMPs from two stations indicate that the Scaling Three-NCM method

137 estimating the parameters of GEV distributions for the specific durations $(\lambda t)$ provides the most 138 accurate quantiles with the observed values. Therefore, this software package uses the Scaling

139 Three-NCM method in order to estimate the parameters of GEV distributions for shorter durations.

\subsection{Error Adjustment Function with Climate Change Scenario Outputs}

For climate change impact studies or flood risk studies under climate change, the daily

142 AMPs are extracted from the downscaled daily precipitation series given from different GCM-

143 based climate change scenarios. However, it is usually expected that these downscaled AMPs are

144 not comparable to the observed extreme values. A bias-correction procedure is, therefore, required

145 to improve the accuracy of the downscaled AMPs at a given site. The proposed procedure is 146 described in the following (Nguyen et al., 2007, Yeo, 2014):

$$
e_{\tau}=y_{\tau}^{o}-\hat{y}_{\tau}
$$

147 in which $y_{\tau}^{o}$ is the observed daily AMP at a probability level $\tau$, and $\hat{y}_{\tau}$ is the estimated daily AMP

148 with each GCM scenario, and $e_{\tau}$ is the residual associated with $\hat{y}_{\tau}$. The residual $\left(e_{\tau}\right)$ is modelled 149 by the second order polynomial regression.

$$
e_{\tau}=m_{0}+m_{1} \hat{y}_{\tau}+m_{2} \hat{y}_{\tau}^{2}+\varepsilon
$$


150 where $m_{0}, m_{1}$, and $m_{2}$ are regression coefficients in the function, $\hat{y}_{\tau}$ is the estimated AMP, and $\varepsilon$

151 is the modeling error term.

152 2.3. Modified Bootstrapping for CIs

153 This section reviews the modified bootstrap technique, which is introduced by Yeo et al.

154 (2020), to determine CIs of the downscaled sub-daily extreme rainfall series. Given the simple

155 scaling properties of annual extreme rainfalls, the proposed technique is conducted by the

156 combination of bootstrapping technique and the Scaling Three-NCM estimation method. Once $n$

157 sets of AMPs are generated for daily duration $T$ from observed or projected AMP series by

158 bootstrapping technique, the $n$ sets of the first three NCMs can be estimated. For constructing CIs,

159 first the upper and lower limits of the NCMs for duration $T$ at a given significance level (e.g. 95\%)

160 are estimated from the $n$ sets of the first three NCMs. The estimated first NCMs for duration $T$ are

161 used to calculate the NCMs for duration $t$, and then parameters $(\xi, \alpha$, and $\kappa)$ of the downscaled

162 GEV distributions for each duration $t$ are calculated by the Scaling Three-NCM estimation method.

163 CIs at a given confidence level are constructed by computing rainfall quantiles from the estimated 164 parameters and Equation 3.

\section{3. Design and Application}

167 Figures 1 and 2 show the main menu of SDExtreme and four main modeling processes: $(i)$ 168 IDF Current Period; (ii) Scaling GEV Model; (iii) IDF Climate Change; and (iv) Confidence 169 Intervals. Full technical details for this software package are described by Yeo et al. (2020). 


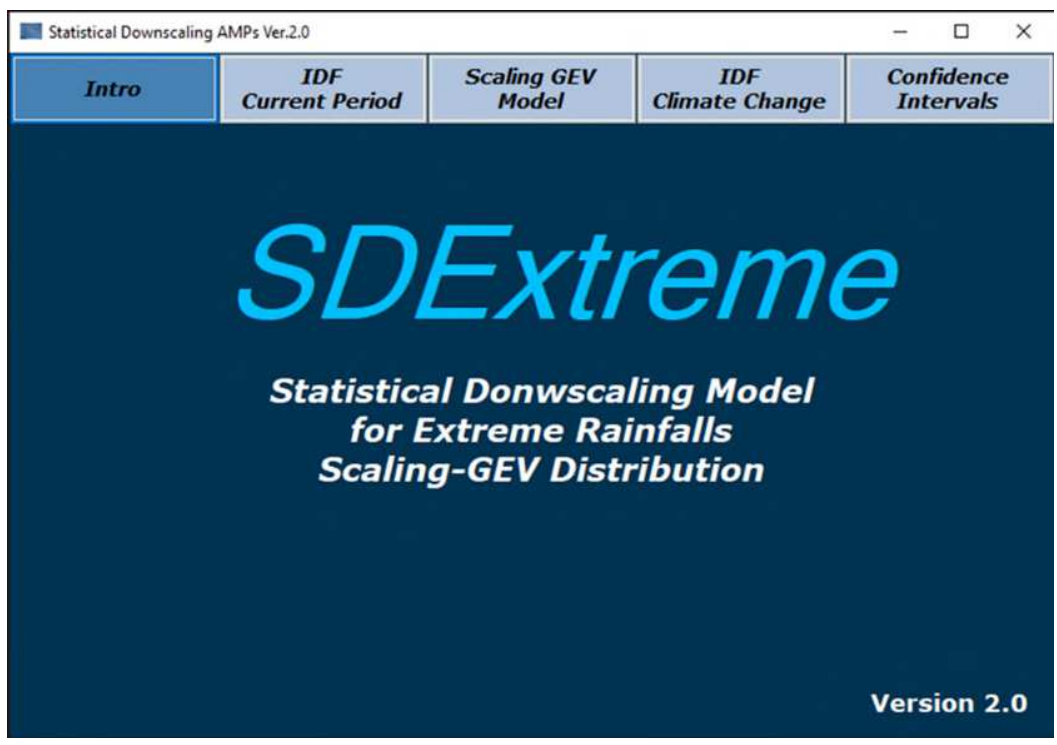

Figure 1. Main menu of SDExtreme.

173

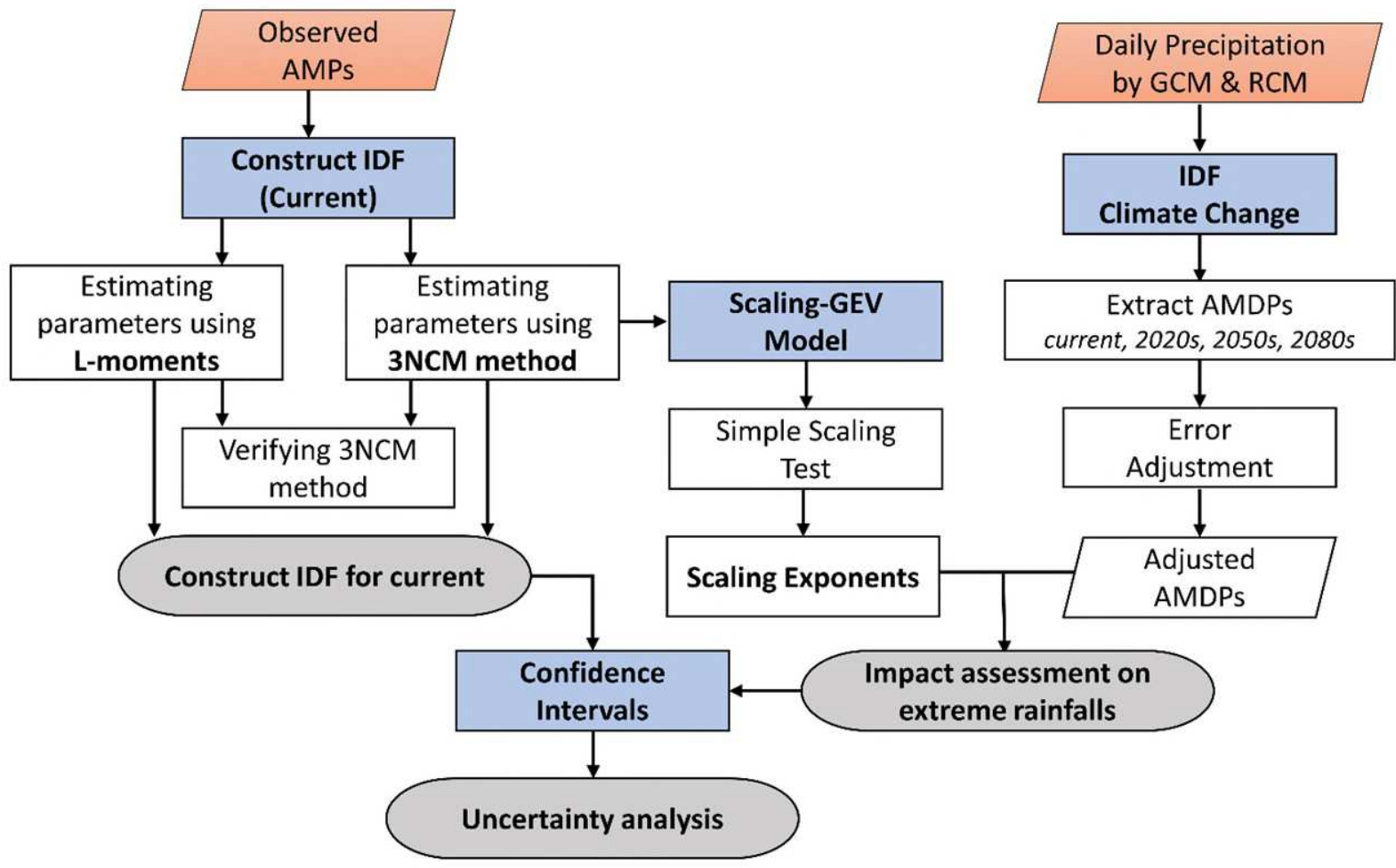

175 Figure 2. SDExtreme computational steps. 


\subsection{IDF Current Period}

The 'IDF Current Period' operation generates current IDF curves given historical AMPs

records. Because both the L-moment and Three-NCM parameter estimation methods are used here,

180 the procedure enables the verification of the quantiles estimated by Three-NCM methods. The user

181 must specify the duration for observed data and the return period to 'SDExtreme.ini' file. After

182 reading the historical records and specified information file, the tool automatically shows the

183 information on data length, the number of intervals, duration, and return period. Finally, this tool

184 provides both graphical and numerical IDF curves so that the user can easily compare the quantiles.

\subsection{Scaling GEV Model}

Given the historical AMP series, the 'Scaling GEV Model' operation conducts the simple

187 scaling properties for them. The log-linearity is observed worldwide for duration between 1-hour

188 up to 24-hours. Regarding the scale-invariance properties for the sub-hourly, a breakpoint at 1-

189 hour (or 30-min) duration has been observed through various regions by the number of studies.

190 For instances, Nhat et al. (2007) investigates the two scaling regimes at Nagoya (Japan), South

191 Korea, Geraldton (Australia), and Malaysia. Breakpoints through many Provinces of Canada are

192 also observed (Bougadis and Adamowski, 2006, Nguyen et al., 2008, Yeo, 2014). Rodríguez et al.

193 (2014) and Chang and Hiong (2013) find breakpoints of scaling properties between sub-hourly

194 and sub-daily duration for Spain and Singapore, respectively. The presence of the breakpoint

195 would imply the transition of extreme rainfall systems (Vu et al., 2018). Therefore, this operation

196 allows the user to find the breakpoint in the first three NCMs in order to avoid the overestimation 197 of NCMs. 
Once the breakpoint is identified, the operation generates a directory, named 'Scaling

199 Exponent,' and saves the estimated scaling exponents $(\beta)$ for both short-/long-durations. The user

200 can examine the linearity of the scaling exponents for both short-/long-durations for the simple

201 properties. The parameters of the downscaled GEV distributions for the duration of sub-hourly

202 and sub-daily can be estimated by the function of 'Estimating Parameters and Quantiles' and saved

203 in the directory of 'Scaling-GEV' with the name of 'Scaled-GEV_Param_Obs.txt.' Finally, the

204 user can compare the estimated quantiles by the scaling-GEV models to the observed values 205 graphically.

\section{3.3. IDF Climate Change}

207 SDExtreme version 2.0 uses the second-degree polynomial equation to improve the 208 accuracy of the downscaled AMPs at a given site. Before the error-adjustment, the 'IDF Climate 209 Change' divides GCMs' output series (1961-2100) into four time periods: 1961-1990, 2020s, 210 2050s, and 2080s. The length of each time period is identical as 30 years. After making the bias-

211 correction adjustment using Equation 10, SDExtreme provides relative root mean square of errors

212 (RMSE) so that the user can identify the improved agreement between the adjusted downscaled

213 AMPs and the observed values as compared to the unadjusted downscaled AMP amounts for the

214 calibration period. The adjusted NCMs are saved in the 'Adjusted-NCM' directory. Finally, this

215 software allows the user to compare the IDF curves with respect to time periods (e.g. calibration

216 period, 2020s, 2050s, and 2080s) after estimating parameters of the downscaled GEV distributions

217 for sub-daily and sub-hourly durations. All parameters, quantiles, and IDF curves for each time 218 period are saved in the 'Scaling-GEV' directory. 
220 The main purpose of the 'Confidence Intervals' operation is to quantify the uncertainties

221 of IDF curves. As a combination of bootstrapping technique and scale-invariance properties of

222 AMPs are used, the user must specify the number of resampling and the significant level.

223 Procedure for calculating CIs for the present is conducted using the historical record, while those

224 for the future are done with climate change scenario outputs. The estimated upper and lower limits

225 of the IDF curves are saved in the 'Confidence-Interval' directory.

\section{4. Applications of SDExtreme}

\subsection{Study area and data}

The feasibility of the proposed SDExtreme was demonstrated with at-site AMP data

230 available at 16 rain gauge stations in the southern Quebec and Ontario provinces (Canada) as

231 shown in Figure 3. Table 1 provides the geographical information on the rain gauge stations used

232 in this study. Historical at-site AMP series were obtained from Canadian Weather Energy and

233 Engineering Datasets (CWEEDS). They were made up of 9 durations (5-min, 10-min, 15-min, 30-

234 min, 1-hr, 2-hr, 6-hr, 12-hr, and 1-day).

235 Table 1. Geographical information of the selected 16 rain gauges.

\begin{tabular}{cccccccc}
\hline Station Name & Province & Latitude & Longitude & Station Name & Province & Latitude & Longitude \\
\hline Delhi & Ontario & 42.87 & -80.55 & Toronto & Ontario & 43.68 & -79.63 \\
Hamilton & Ontario & 43.29 & -79.91 & Windsor & Ontario & 42.28 & -82.96 \\
Kingston & Ontario & 44.24 & -76.48 & Bagotville & Quebec & 48.33 & -71.00 \\
London & Ontario & 43.03 & -81.15 & Drummondville & Quebec & 45.88 & -72.48 \\
Ottawa & Ontario & 45.38 & -75.72 & Mont Joli & Quebec & 48.60 & 68.22 \\
Sault Ste Marie & Ontario & 46.48 & -84.51 & Montreal & Quebec & 45.47 & -73.75 \\
St Thomas & Ontario & 42.77 & -81.21 & St-Hubert & Quebec & 45.52 & -73.42 \\
Thunder Bay & Ontario & 48.38 & -89.25 & Val-D'Or & Quebec & 48.06 & -77.79 \\
\hline
\end{tabular}




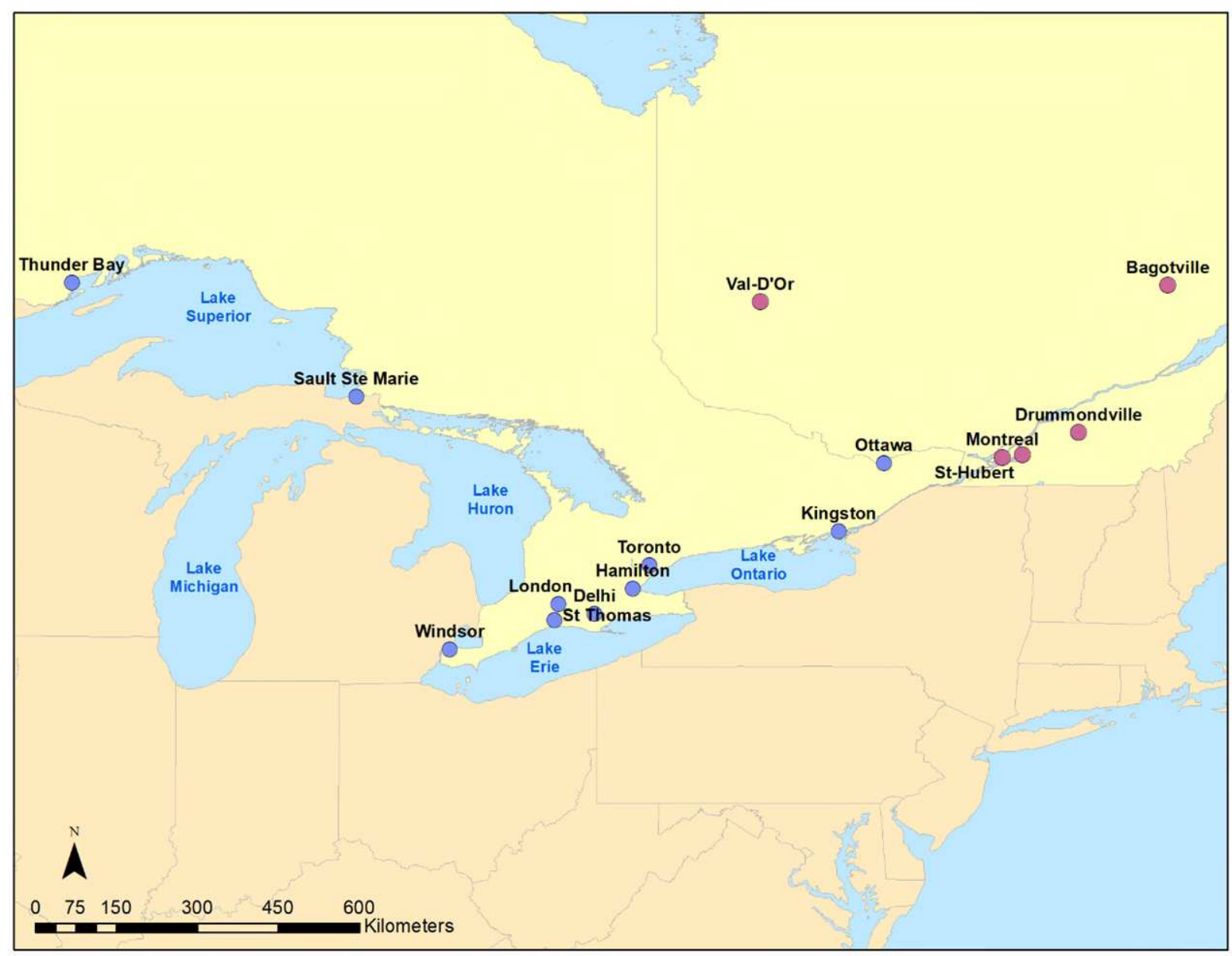

Figure 3. The study area encompasses the southern Quebec and Ontario Provinces (Canada). Red points denote the raingauge stations in Quebec Province, and blue circles do the rain-gauge stations in Ontario Province.

\subsection{Verification of the Three-NCM parameter estimation method}

In the 'IDF Current Period' procedure, SDExtreme provides numerical and graphical

243 results (e.g. quantile plots and IDF curves) in order to evaluate the Three-NCM parameter

244 estimation method using the observed and estimated quantiles by L-moment method. Figure 4

245 shows the quantile plots for duration 5-min and 30-min for the selected representative stations

246 (Toronto International Airport for Ontario province and St. Hubert for Quebec province). Black, 
blue, and red dots represent observed, estimated quantiles by L-moments and the Three-NCMs

248 methods, respectively. Good agreement between the estimated by two estimation methods was

249 observed for both stations. Numerical IDF curves were obtained using the conventional parameter

250 estimation method and the Three-NCMs method for both Toronto and St. Hubert stations in Tables

2512 and 3 , respectively.

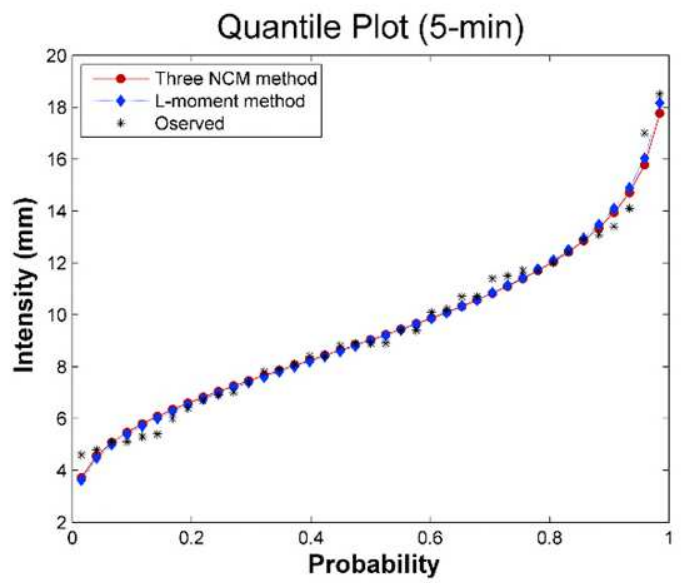

(A)

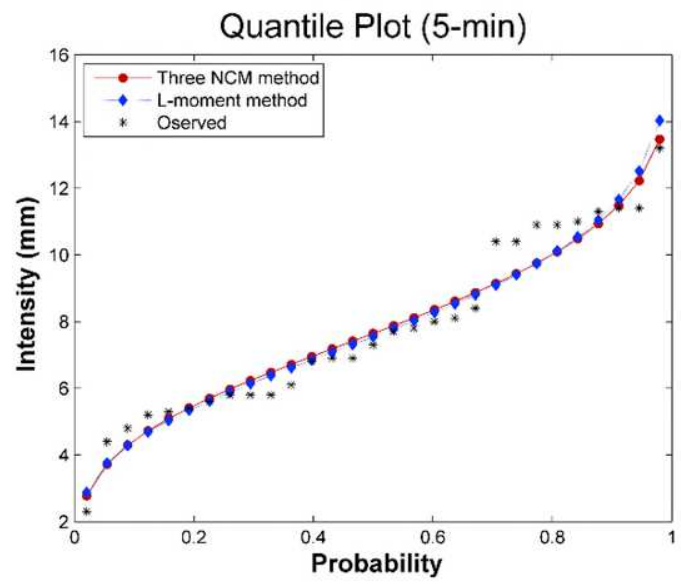

(C)

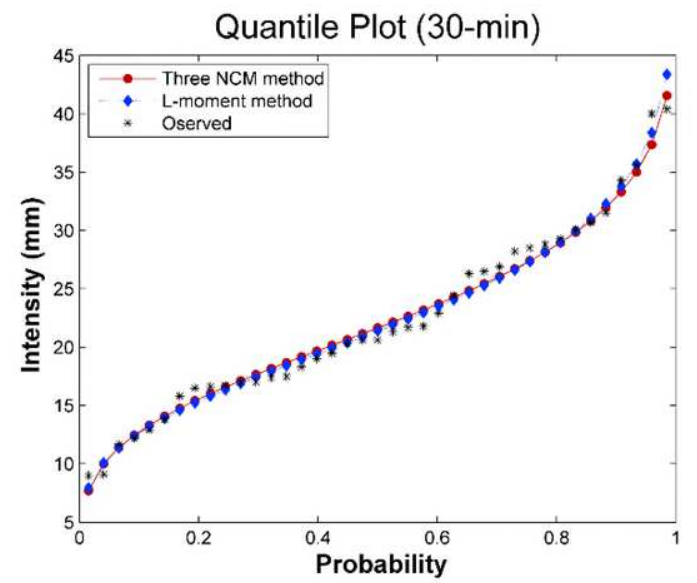

(B)

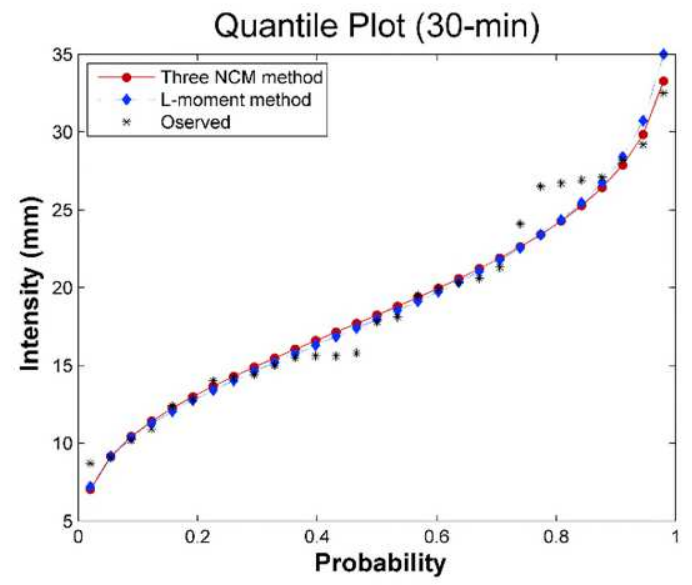

(D)

Figure 4. Quantile plots comparing the observed to the estimated values by L-moments method and Three-NCM method for the selected durations (e.g. 5-min and 30-min) at Toronto (Ontario) and St. Hubert (Quebec), respectively. (A) 5-min quantile plot for Dorval, (B) 30-min quantile plot for Toronto, (C) 5-min quantile plot for St. Hubert, and (D) 30-min quantile plot for St. Hubert. The black asterisk represents the observed values, the red line does the quantiles estimated by Three-NCM method, and blue line denotes those by L-moment method. 
Table 2. Numerical IDF curves (the current period) using the L-moment method and the Three-NCMs method for Toronto station (Ontario): (A) numerical IDF curves by L-moments method and (B) those by Thee-NCMs method.

(A) IDF Curves estimated by L-moments

\begin{tabular}{|c|c|c|c|c|c|c|c|c|c|}
\hline \multirow{2}{*}{$\begin{array}{l}\text { Return } \\
\text { Period }\end{array}$} & \multicolumn{9}{|c|}{ Duration (minutes) } \\
\hline & 5 & 10 & 15 & 30 & 60 & 120 & 360 & 720 & 1440 \\
\hline 2 & 107.98 & 79.6 & 65.27 & 42.79 & 23.8 & 13.85 & 5.85 & 3.3 & 1.92 \\
\hline 5 & 144.22 & 105.86 & 87.46 & 57.56 & 31.84 & 18.59 & 7.97 & 4.44 & 2.49 \\
\hline 20 & 186.71 & 135.04 & 112.55 & 74.53 & 42.41 & 25.62 & 11.27 & 6.46 & 3.54 \\
\hline 50 & 211.21 & 151.06 & 126.53 & 84.13 & 49.19 & 30.66 & 13.75 & 8.17 & 4.45 \\
\hline 100 & 228.45 & 161.96 & 136.15 & 90.79 & 54.31 & 34.76 & 15.83 & 9.72 & 5.3 \\
\hline
\end{tabular}

(B) IDF Curves estimated by Three-NCMs

\begin{tabular}{cccccccccc}
\hline $\begin{array}{c}\text { Return } \\
\text { Period }\end{array}$ & 5 & 10 & 15 & 30 & 60 & 120 & 360 & 720 & 1440 \\
\hline 2 & 108.44 & 80.26 & 66.07 & 43.31 & 24.3 & 14.17 & 6.04 & 3.47 & 2.01 \\
5 & 143.59 & 105.56 & 87.34 & 57.52 & 32.08 & 18.92 & 8.23 & 4.7 & 2.66 \\
20 & 184.06 & 132.45 & 109.85 & 72.82 & 41.17 & 25.08 & 11.06 & 6.28 & 3.5 \\
50 & 207.01 & 146.59 & 121.64 & 80.96 & 46.39 & 28.97 & 12.86 & 7.29 & 4.03 \\
100 & 222.96 & 155.94 & 129.42 & 86.39 & 50.05 & 31.89 & 14.2 & 8.04 & 4.42 \\
\hline
\end{tabular}

Table 3. Numerical IDF curves (the current period) using the L-moment estimation method and the Three-NCMs method for St. Hubert station (Quebec): (A) numerical IDF curves by L-moments method and (B) those by Thee-NCMs method.

(A) IDF Curves estiamated by L-moments

\begin{tabular}{ccccccccccc}
\hline \multirow{2}{*}{$\begin{array}{c}\text { Return } \\
\text { Period }\end{array}$} & \multicolumn{10}{c}{ Duration (minutes) } \\
\cline { 2 - 11 } & 5 & 10 & 15 & 30 & 60 & 120 & 360 & 720 & 1440 \\
\hline 2 & 90.51 & 66.35 & 54.53 & 35.91 & 21.21 & 12.26 & 5.7 & 3.57 & 2.11 \\
5 & 120.23 & 87.78 & 73 & 48.22 & 29.29 & 16.65 & 7.4 & 4.52 & 2.57 \\
20 & 152.01 & 110.52 & 94.75 & 62.3 & 39.7 & 23.09 & 9.81 & 5.68 & 3.03 \\
50 & 168.83 & 122.47 & 107.37 & 70.23 & 46.27 & 27.64 & 11.46 & 6.36 & 3.25 \\
100 & 179.99 & 130.36 & 116.26 & 75.73 & 51.18 & 31.33 & 12.76 & 6.85 & 3.4 \\
\hline
\end{tabular}

(B) IDF Curves estimated by Three-NCMs

\begin{tabular}{ccccccccccc}
\hline \multirow{2}{*}{$\begin{array}{c}\text { Return } \\
\text { Period }\end{array}$} & \multicolumn{10}{c}{ Duration (minutes) } \\
\cline { 2 - 10 } & 5 & 10 & 15 & 30 & 60 & 120 & 360 & 720 & 1440 \\
\hline 2 & 91.72 & 66.36 & 55.11 & 36.48 & 21.67 & 12.54 & 5.78 & 3.62 & 2.11 \\
5 & 120.11 & 87.15 & 72.97 & 48.13 & 29.38 & 16.88 & 7.46 & 4.52 & 2.55 \\
20 & 148.17 & 109.29 & 92.87 & 60.37 & 38.33 & 22.51 & 9.63 & 5.53 & 2.98 \\
50 & 161.96 & 120.96 & 103.83 & 66.74 & 43.45 & 26.07 & 11.01 & 6.09 & 3.19 \\
100 & 170.66 & 128.69 & 111.29 & 70.91 & 47.03 & 28.73 & 12.04 & 6.47 & 3.32 \\
\hline
\end{tabular}




\subsection{Investigation of scale-invariant properties}

Figure 5 shows the scaling relationships with respect to all duration. SDExtreme provides

268 the R-square plot for determining the breakpoint to identify scaling properties at two different

269 regimes of durations. From Figure 4-(B) and (D), case 2 (30-min) are determined for both Toronto

270 and St. Huber stations. Table 4 shows scaling exponents (i.e. slopes of the NCMs) and the duration

271 when breakpoints are observed. The breakpoints at thirteen stations are located at 30-min. While

272 the points at Ottawa and Hamilton are of 60-min, the point at Kingston is located at 360-min. The

273 spatial distributions of exponents are shown in Figure 6. Figure 6-(A) is for the scaling exponents

274 for the duration before breakpoints and Figure 6-(B) for the duration after breakpoints. Because

275 the scaling exponent is a ratio of extreme precipitation intensities to duration, a station with a

276 bigger value of the scaling exponent would have more intensive extreme rainfall than a station

277 with a lower value of the scaling exponent. In general, rain gauge stations in the southern portion

278 have more intensive rainfall during short periods.

279 To examine the simple scaling properties of the AMP series, SDExtreme carries out the 280 simple scale test with graphically and numerically. As shown in Figure 7, the linearity of the 281 scaling exponents with the moment order supports the assumption that the extreme rainfall series 282 can be described by a simple scaling model for both stations. 


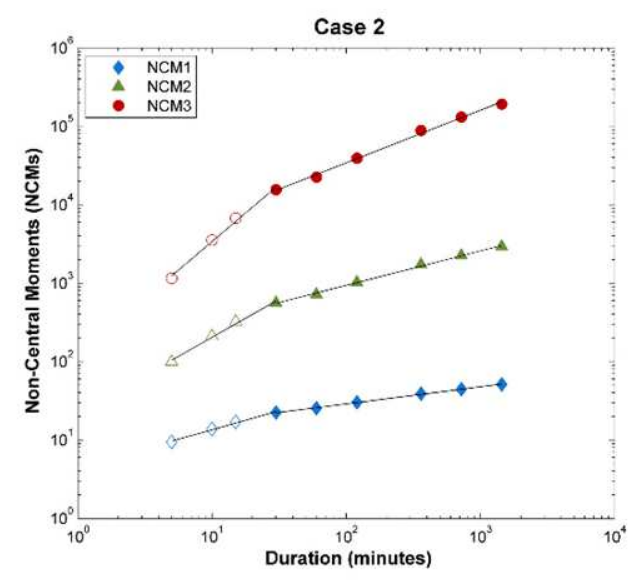

(A)

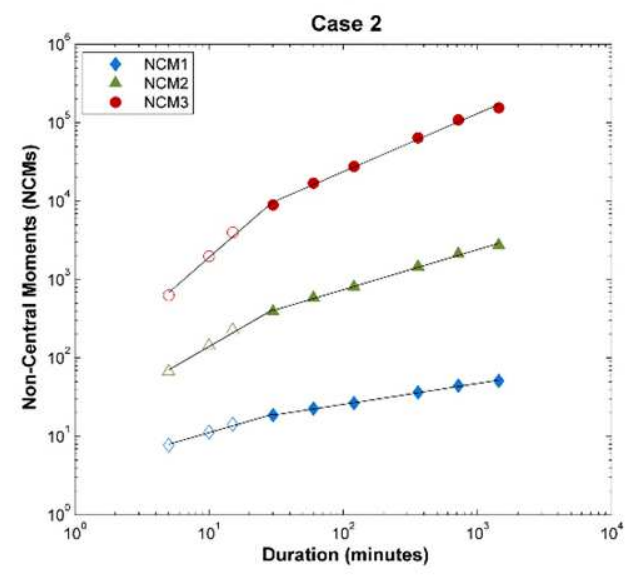

(C)

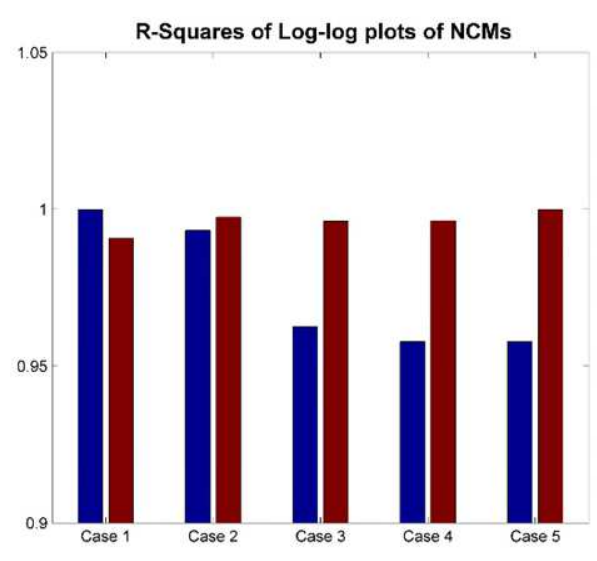

(B)

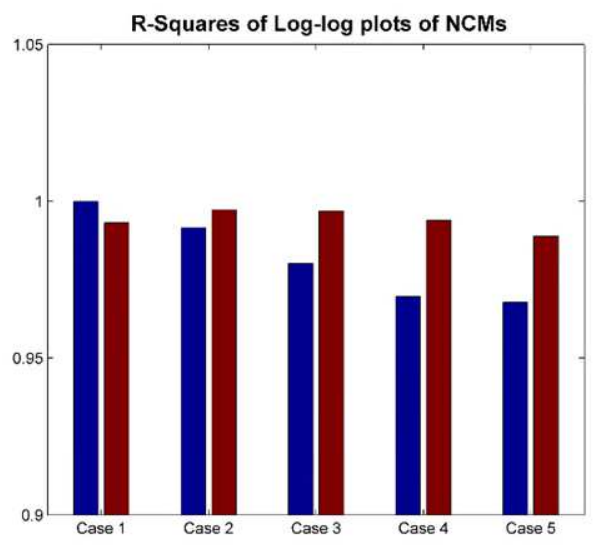

Figure 5. Log-log plots of non-central moments (NCMs) of the first three orders against several durations for (A) Toronto and (C) St. Hubert. Blue diamonds denote the first order NCMs, green triangles do the second order NCMs, and red dots represent the third order NCMs. R-square plots are provided for detecting the best case to demonstrate two scaling regimes.

Table 4. Scaling exponents of the third NCMs for the shorter and longer durations, and the durations for the break-points.

\begin{tabular}{cccc}
\hline Station Name & $\begin{array}{c}\text { Scaling Exponents of the } \\
\text { third NCMs } \\
\text { (short duration) }\end{array}$ & $\begin{array}{c}\text { Scaling Exponents of the third } \\
\text { NCMs } \\
\text { (long duration) }\end{array}$ & $\begin{array}{c}\text { Breakpoint } \\
\text { Duration (min) }\end{array}$ \\
\hline Delhi & 1.467 & 0.911 & 30 \\
Hamilton & 1.376 & 0.591 & 60 \\
Kingston & 1.179 & 0.955 & 360 \\
London & 1.371 & 0.661 & 30 \\
Ottawa & 1.287 & 0.544 & 60 \\
Sault Ste Marie & 1.397 & 0.818 & 30 \\
St Thomas & 1.261 & 0.759 & 30
\end{tabular}




\begin{tabular}{cccc} 
Thunder Bay & 1.548 & 0.821 & 30 \\
Toronto & 1.477 & 0.632 & 30 \\
Windsor & 1.552 & 0.598 & 30 \\
Bagotville & 1.612 & 0.629 & 30 \\
Drummondville & 1.401 & 0.77 & 30 \\
Mont Joli & 1.356 & 1.041 & 30 \\
Montreal & 1.54 & 0.562 & 30 \\
St-Hubert & 1.491 & 0.741 & 30 \\
Val-D'Or & 1.353 & 0.69 & 30 \\
\hline
\end{tabular}




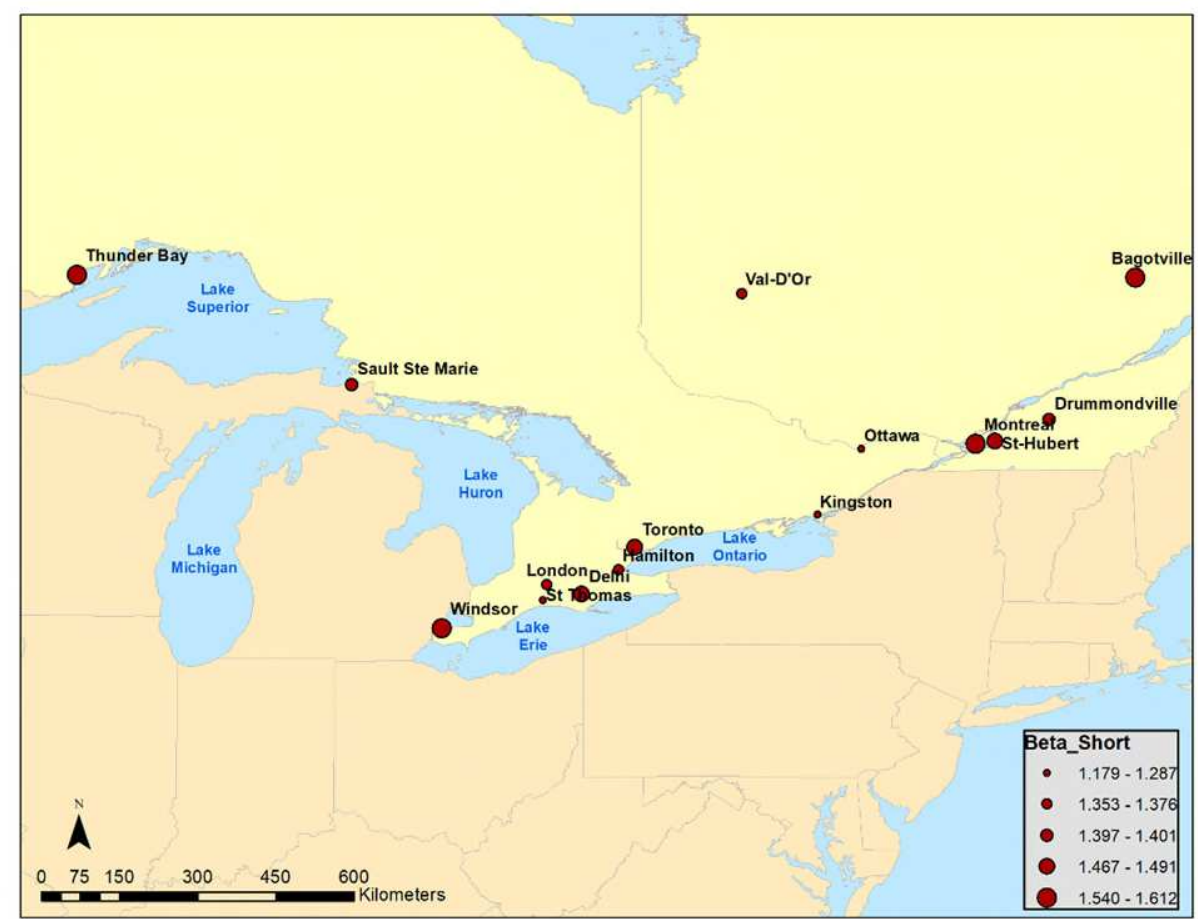

(A)

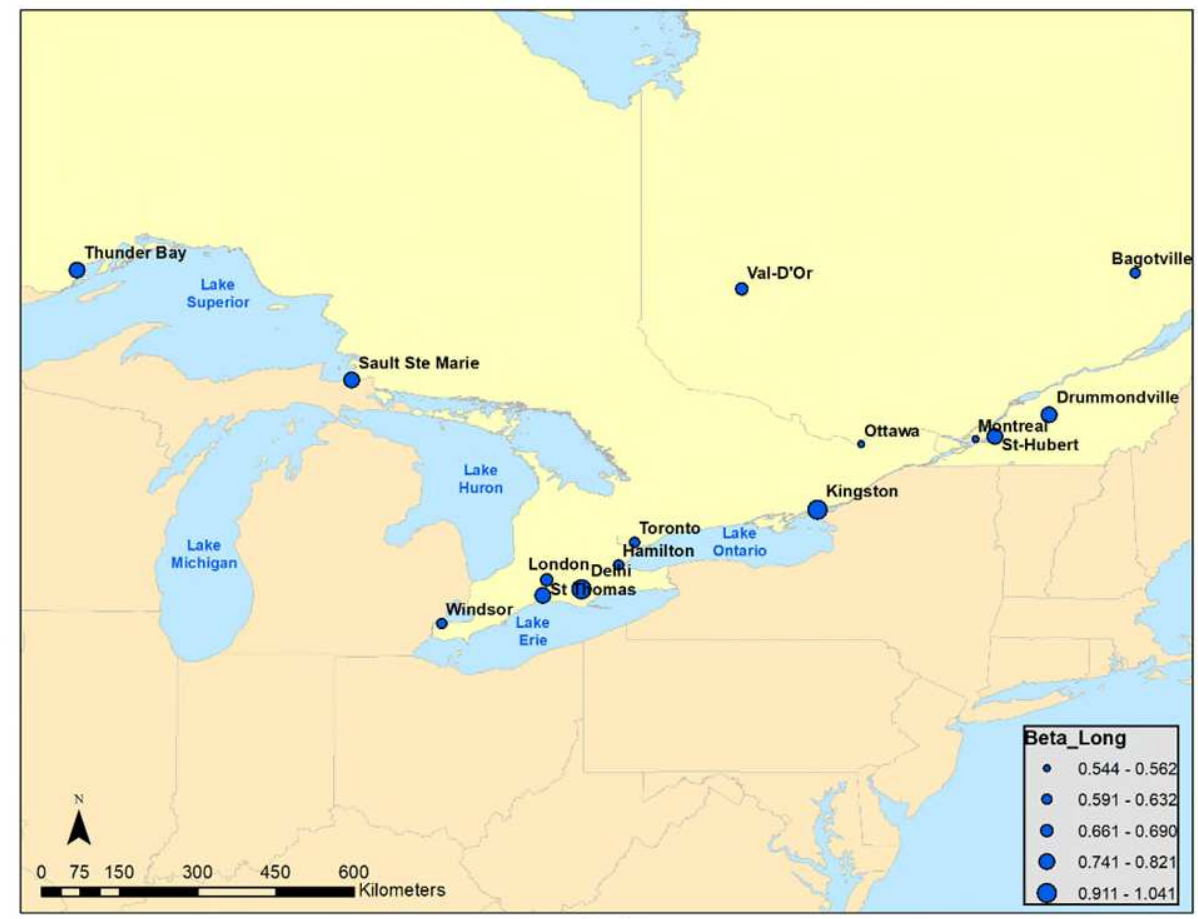

(B)

292 Figure 6. Spatial distributions of scaling exponents for the third NCMs. (A) scaling exponents for the shorter durations and 293 (B) for the longer durations. 


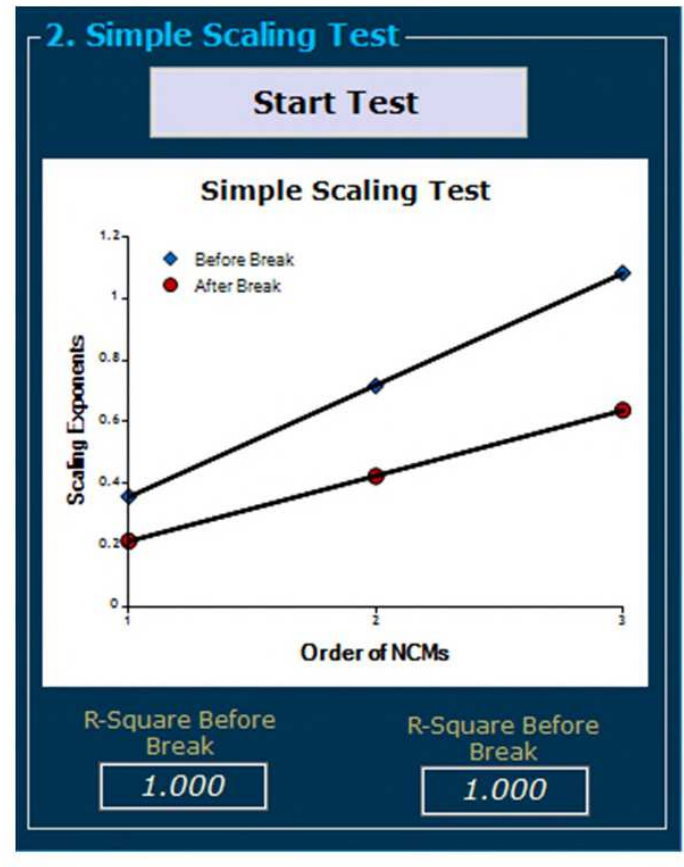

(A)

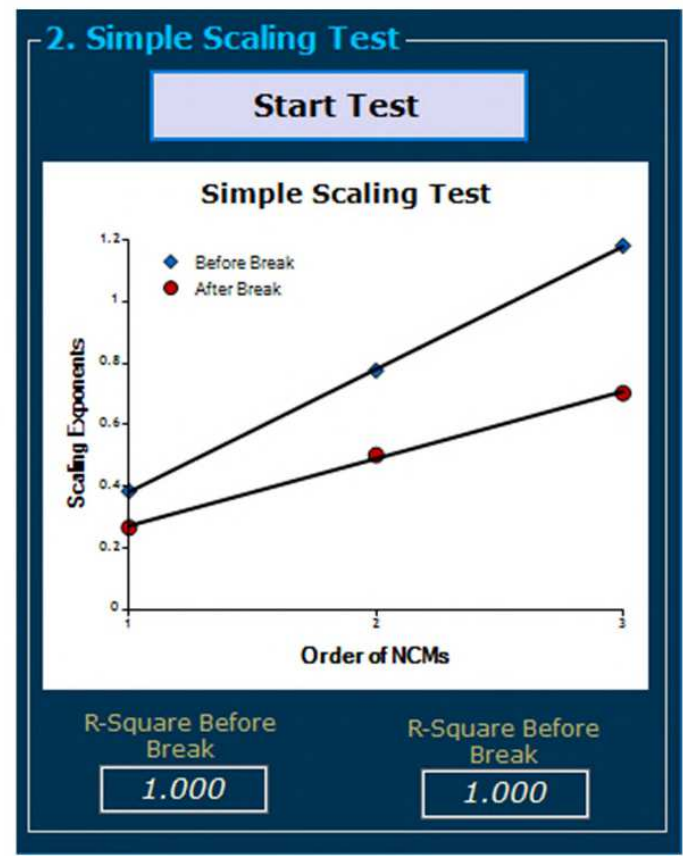

(B)
295

296

297

298

Figure 7. Plots of the scaling exponents against the order of NCMs of AMP for (A) Toronto and (B) St. Hubert stations. Blue-diamonds represent the scaling exponents for the shorter duration and red-dots denote those for longer duration.

On the basis of the simple scaling relationship, Figure 6 shows the comparison between the observed and estimated AMPs by L-moments and scaling GEV distributions for 5-min and 30min durations for Toronto and St. Hubert stations. It can be seen that the quantiles derived from the daily AMPs using the established scaling relationships agree very well with those values given by the conventional fitted GEV distribution as well as with the observed values. Similar results were found for other durations and stations. 


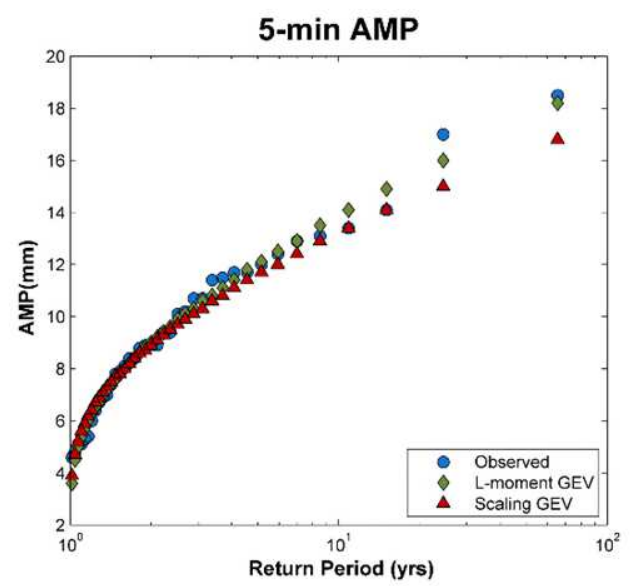

(A)

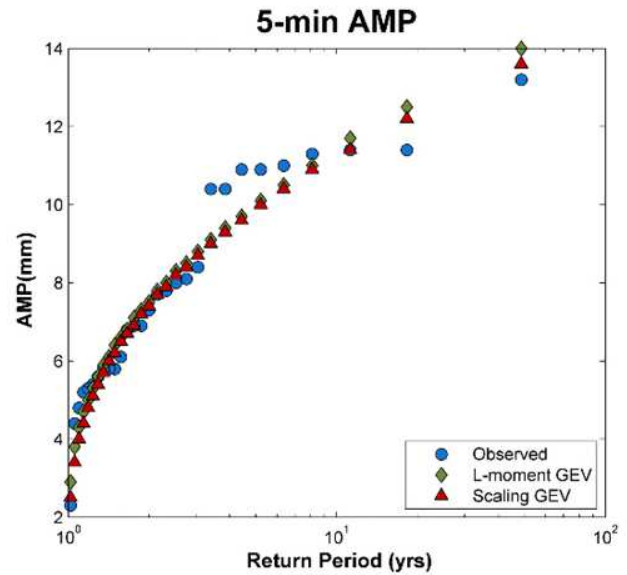

(C)

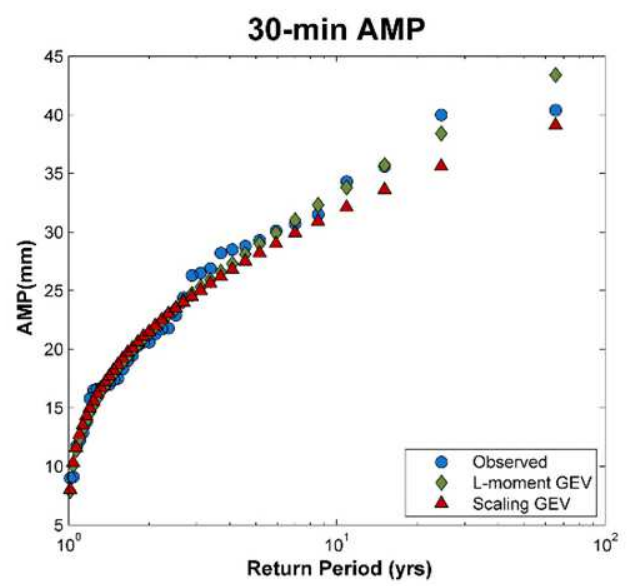

(B)

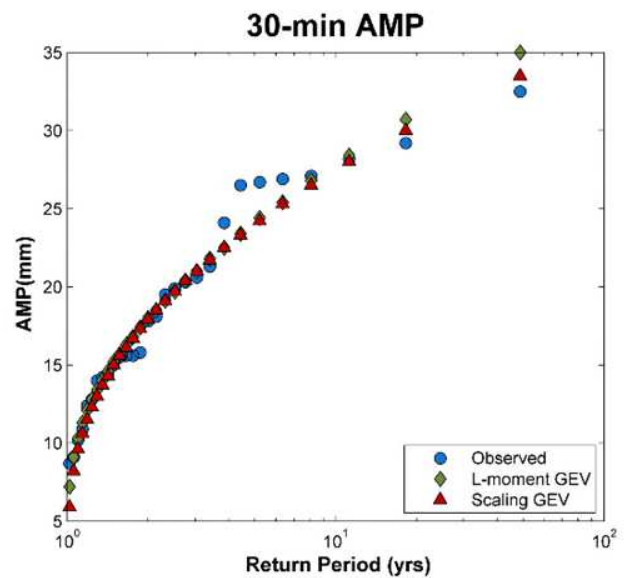

(D) used. As a statistical downscaling, SDRain proposed by Yeo et al. (2019) was calibrated and used

314 to generate daily precipitation time series for Dorval station. A set of significant global
Figure 8. IDF curves of AMPs for 5-min (or 10-min) and 30-min durations estimated by L-moments and the simple scaling models for Toronto (A, B) and St. Hubert (C, D), respectively. Blue dots represent the observed rainfall intensities, green diamonds do the estimated

\subsection{Update IDF curve for the future period}

To illustrate SDExtreme for future IDF curves, two different downscaling methods were 
315 atmospheric reanalysis variables of the NCEP/NCAR (Kalnay et al., 1996) given by the second-

316 generation Canadian Earth System Model (CanESM2) was used to establish statistical

317 downscaling models. Once the spatial downscaling model with SDRain was calibrated, future

318 weather conditions were projected with the three climate change scenarios (RCP 2.6, RCP 4.5, and

319 RCP 8.5), where RCP denotes a representative concentration pathway. As a dynamical

320 downscaling method, the Canadian Regional Climate Model (CanRCM4) with $0.22^{\circ}$ grid

321 resolution was used. The downscaled daily precipitation series of climate variables for the grid

322 point nearest to each rain gauge station were used. A secondary quantile mapping was

323 implemented to account for uncertainty in the CanRCM4 coming from climate systems.

324 Tables 5 9 show the numerical IDF relations for Ottawa station given by SDExtreme based 325 on the scaling GEV model for three time periods (2020s, 2050s, and 2080s) under three different

326 climate change scenarios (RCP2.6, RCP4.5, and RCP8.5) provided by CanESM2 and two 327 scenarios (RCP4.5 and RCP8.5) by CanRCM4. For the illustration purposes, Figure 9 shows the 328 plot of daily AMPs corresponding to 100-year return period simulated by SDExtreme and the three 329 greenhouse gas emission scenarios given by CanESM2 and CanRCM4. It is found that the 330 estimated 100-year daily AMPs exhibit similarly continuous increasing trends from the current 331 period to 2020s, 2050, and 2080s. With CanESM2, the intensity increases from about $3.6 \mathrm{~mm} / \mathrm{h}$ 332 (current) to $3.70 \mathrm{~mm} / \mathrm{h}$ (RCP 2.6), to $3.74 \mathrm{~mm} / \mathrm{h}$ (RCP 4.5), and to $3.79 \mathrm{~mm} / \mathrm{h}$ (RCP 8.5 ), 333 respectively. However, CanRCM4 shows different patterns from the estimated intensities by 334 CanESM2. 


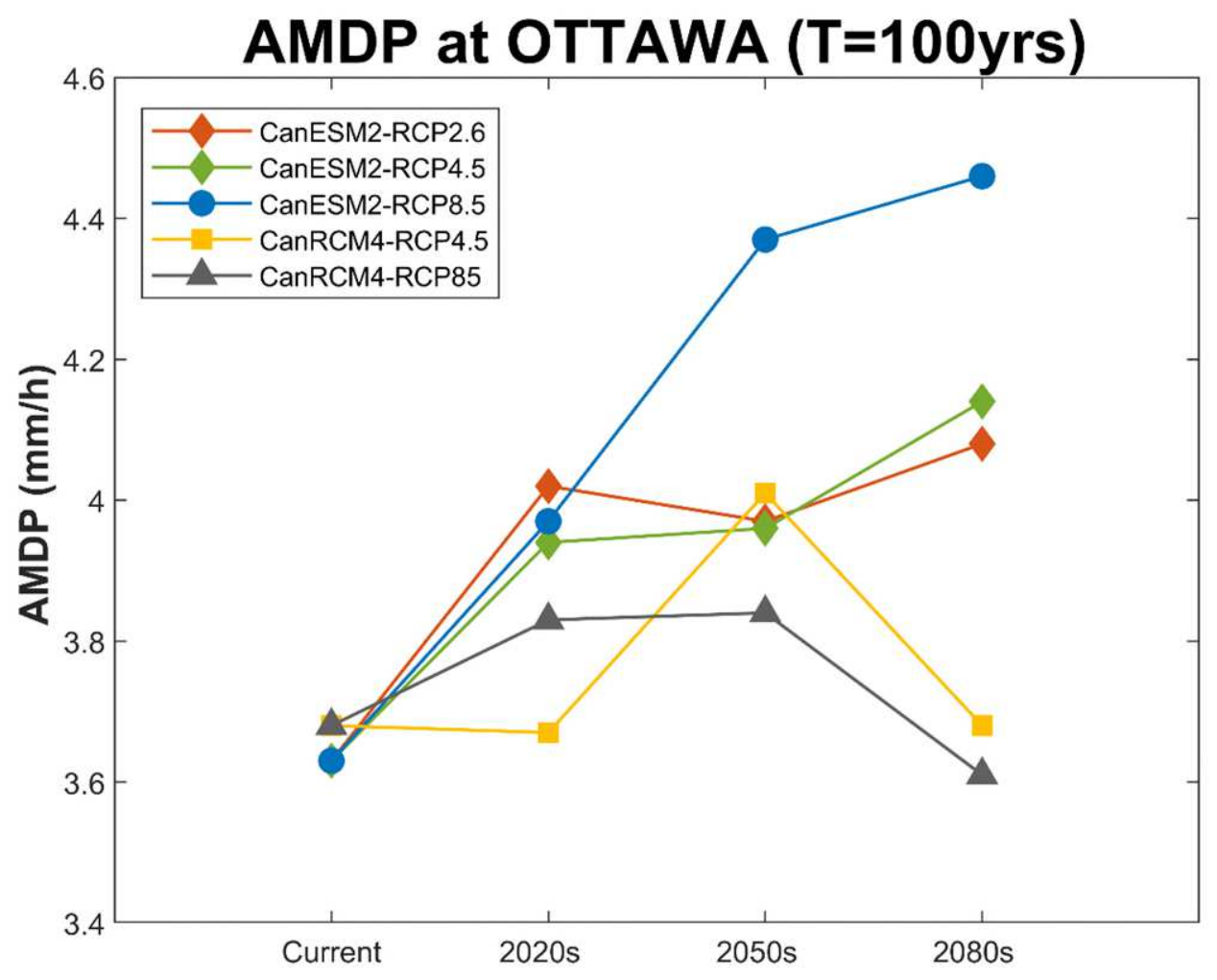

Figure 9. Estimated daily AMPs corresponding to 100-year return period for the current and future periods (2020s, 2050s, and 2080s) for Ottawa station.

Table 5. Numerical IDF curves of AMP estimated by SDExtreme based on scaling GEV model under RCP 2.6 climate change scenario by CanESM2 for Ottawa rain gauge station.

(A) Period of 2020 s

\begin{tabular}{|c|c|c|c|c|c|c|c|c|c|}
\hline \multirow{2}{*}{$\begin{array}{l}\text { Return } \\
\text { Period }\end{array}$} & \multicolumn{9}{|c|}{ Duration $(\min ): \mathrm{mm} / \mathrm{h}$} \\
\hline & 5 & 10 & 15 & 30 & 60 & 120 & 360 & 720 & 1440 \\
\hline 2 & 114.96 & 75.56 & 59.14 & 39.08 & 25.82 & 14.82 & 6.14 & 3.53 & 2.03 \\
\hline 5 & 144.62 & 96.89 & 76.63 & 51.53 & 34.62 & 19.65 & 8.01 & 4.55 & 2.59 \\
\hline 20 & 180.73 & 124.01 & 99.29 & 67.68 & 46.03 & 25.93 & 10.42 & 5.85 & 3.28 \\
\hline 50 & 202.31 & 140.89 & 113.65 & 77.91 & 53.27 & 29.91 & 11.95 & 6.67 & 3.71 \\
\hline 100 & 217.84 & 153.38 & 124.4 & 85.58 & 58.69 & 32.89 & 13.1 & 7.28 & 4.02 \\
\hline
\end{tabular}

(B) Period of 2050s

\begin{tabular}{|c|c|c|c|c|c|c|c|c|c|}
\hline \multirow{2}{*}{$\begin{array}{l}\text { Return } \\
\text { Period }\end{array}$} & \multicolumn{9}{|c|}{ Duration $(\min ): \mathrm{mm} / \mathrm{h}$} \\
\hline & 5 & 10 & 15 & 30 & 60 & 120 & 360 & 720 & 1440 \\
\hline 2 & 120.09 & 78.8 & 61.65 & 40.59 & 26.82 & 15.39 & 6.4 & 3.68 & 2.12 \\
\hline 5 & 148.68 & 99.65 & 78.83 & 52.83 & 35.52 & 20.16 & 8.23 & 4.68 & 2.66 \\
\hline 20 & 181.76 & 125.30 & 100.51 & 68.71 & 46.81 & 26.34 & 10.56 & 5.92 & 3.31 \\
\hline 50 & 200.61 & 140.78 & 113.91 & 78.78 & 53.96 & 30.26 & 12.02 & 6.67 & 3.69 \\
\hline
\end{tabular}




\begin{tabular}{|rrrrrrrrrr|}
\hline 100 & 213.76 & 152.00 & 123.77 & 86.32 & 59.32 & 33.20 & 13.10 & 7.23 & 3.97 \\
\hline
\end{tabular}

Table 6. Numerical IDF curves of AMP estimated by SDExtreme based on scaling GEV model under RCP 4.5 climate change scenario by CanESM2 for Ottawa rain gauge station.

(A) Period of 2020s

\begin{tabular}{|rrrrrrrrrr|}
\hline $\begin{array}{c}\text { Return } \\
\text { Period }\end{array}$ & \multicolumn{9}{c}{ Duration (min): $\mathrm{mm} / \mathrm{h}$} \\
\hline 2 & 111.69 & 73.43 & 57.53 & 38.01 & 25.12 & 14.41 & 5.98 & 3.43 & 1.98 \\
5 & 140.80 & 94.33 & 74.68 & 50.22 & 33.74 & 19.15 & 7.80 & 4.43 & 2.52 \\
20 & 176.61 & 121.10 & 96.92 & 66.04 & 44.91 & 25.30 & 10.17 & 5.72 & 3.21 \\
50 & 198.21 & 137.87 & 111.01 & 76.07 & 52.00 & 29.20 & 11.67 & 6.53 & 3.63 \\
100 & 213.87 & 150.34 & 121.58 & 83.59 & 57.30 & 32.120 & 12.8 & 7.13 & 3.94 \\
\hline
\end{tabular}

(B) Period of 2050s

\begin{tabular}{|rrrrrrrrrr|r|}
\hline $\begin{array}{r}\text { Return } \\
\text { Period }\end{array}$ & \multicolumn{10}{c}{ Duration (min): $\mathrm{mm} / \mathrm{h}$} \\
\hline 2 & 117.74 & 77.29 & 60.48 & 39.85 & 26.33 & 15.11 & 6.28 & 3.61 & 2.08 \\
5 & 146.55 & 98.20 & 77.67 & 52.09 & 35.01 & 19.87 & 8.11 & 4.61 & 2.62 \\
20 & 180.32 & 124.12 & 99.51 & 67.97 & 46.28 & 26.05 & 10.45 & 5.86 & 3.28 \\
50 & 199.79 & 139.88 & 113.07 & 78.03 & 53.41 & 29.96 & 11.93 & 6.63 & 3.67 \\
100 & 213.47 & 151.36 & 123.10 & 85.57 & 58.76 & 32.90 & 13.02 & 7.19 & 3.96 \\
\hline
\end{tabular}

(C) Period of $2080 \mathrm{~s}$

\begin{tabular}{|rrrrrrrrrr|}
\hline $\begin{array}{r}\text { Return } \\
\text { Period }\end{array}$ & \multicolumn{8}{c}{ Duration (min): $\mathrm{mm} / \mathrm{h}$} \\
\hline 2 & 122.89 & 80.67 & 63.11 & 41.58 & 27.47 & 15.77 & 6.55 & 3.77 & 2.17 \\
5 & 153.19 & 102.63 & 81.17 & 54.42 & 36.58 & 20.76 & 8.47 & 4.82 & 2.74 \\
20 & 188.63 & 129.82 & 104.07 & 71.07 & 48.38 & 27.24 & 10.93 & 6.13 & 3.43 \\
50 & 209.02 & 146.32 & 118.27 & 81.62 & 55.86 & 31.34 & 12.47 & 6.93 & 3.84 \\
100 & 223.34 & 158.32 & 128.76 & 89.53 & 61.47 & 34.42 & 13.62 & 7.52 & 4.14 \\
\hline
\end{tabular}
change scenario by CanESM2 for Ottawa rain gauge station.

(A) Period of 2020s

Duration (min): $\mathrm{mm} / \mathrm{h}$ 


\begin{tabular}{|rrrrrrrrrr|}
$\begin{array}{r}\text { Return } \\
\text { Period }\end{array}$ & \multicolumn{1}{c}{5} & 10 & 15 & 30 & 60 & 120 & 360 & 720 & 1440 \\
\hline 2 & 115.52 & 75.85 & 59.35 & 39.13 & 25.86 & 14.84 & 6.16 & 3.55 & 2.04 \\
5 & 145.15 & 97.20 & 76.86 & 51.54 & 34.63 & 19.66 & 8.02 & 4.56 & 2.60 \\
20 & 180.18 & 123.79 & 99.16 & 67.64 & 46.02 & 25.92 & 10.41 & 5.84 & 3.27 \\
50 & 200.53 & 140.02 & 113.06 & 77.85 & 53.24 & 29.88 & 11.92 & 6.63 & 3.68 \\
100 & 214.92 & 151.87 & 123.36 & 85.50 & 58.64 & 32.85 & 13.04 & 7.21 & 3.97 \\
\hline
\end{tabular}

(B) Period of 2050s

\begin{tabular}{|rrrrrrrrrr|}
\hline $\begin{array}{c}\text { Return } \\
\text { Period }\end{array}$ & \multicolumn{9}{c}{ Duration (min): $\mathrm{mm} / \mathrm{h}$} \\
\hline 2 & 124.20 & 81.64 & 63.93 & 42.24 & 27.92 & 16.02 & 6.64 & 3.82 & 2.20 \\
5 & 156.58 & 104.89 & 82.98 & 55.80 & 37.49 & 21.28 & 8.67 & 4.93 & 2.80 \\
20 & 196.20 & 134.56 & 107.71 & 73.39 & 49.91 & 28.12 & 11.30 & 6.35 & 3.56 \\
50 & 219.98 & 153.08 & 123.37 & 84.54 & 57.78 & 32.45 & 12.97 & 7.25 & 4.03 \\
100 & 237.17 & 166.81 & 135.11 & 92.90 & 63.68 & 35.69 & 14.22 & 7.92 & 4.37 \\
\hline
\end{tabular}

(C) Period of 2080s

\begin{tabular}{|c|c|c|c|c|c|c|c|c|c|}
\hline \multirow{2}{*}{$\begin{array}{l}\text { Return } \\
\text { Period }\end{array}$} & \multicolumn{9}{|c|}{ Duration $(\min ): \mathrm{mm} / \mathrm{h}$} \\
\hline & 5 & 10 & 15 & 30 & 60 & 120 & 360 & 720 & 1440 \\
\hline 2 & 132.57 & 87.18 & 68.36 & 45.16 & 29.84 & 17.12 & 7.10 & 4.08 & 2.35 \\
\hline 5 & 163.17 & 109.57 & 86.92 & 58.52 & 39.35 & 22.33 & 9.09 & 5.15 & 2.92 \\
\hline 20 & 201.17 & 138.48 & 111.01 & 75.85 & 51.70 & 29.08 & 11.66 & 6.54 & 3.66 \\
\hline 50 & 224.30 & 156.72 & 126.27 & 86.84 & 59.52 & 33.36 & 13.29 & 7.42 & 4.12 \\
\hline 100 & 241.17 & 170.35 & 137.70 & 95.07 & 65.39 & 36.57 & 14.52 & 8.08 & 4.46 \\
\hline
\end{tabular}

349 Table 8. Numerical IDF curves of AMP estimated by SDExtreme based on scaling GEV model under RCP 4.5 climate 350 change scenario by CanRCM4 for Ottawa rain gauge station.

(A) Period of 2020s

\begin{tabular}{|c|c|c|c|c|c|c|c|c|c|}
\hline \multirow{2}{*}{$\begin{array}{l}\text { Return } \\
\text { Period }\end{array}$} & \multicolumn{9}{|c|}{ Duration $(\min ): \mathrm{mm} / \mathrm{h}$} \\
\hline & 5 & 10 & 15 & 30 & 60 & 120 & 360 & 720 & 1440 \\
\hline 2 & 126.79 & 83.17 & 65.08 & 42.93 & 28.35 & 16.28 & 6.76 & 3.89 & 2.24 \\
\hline 5 & 147.2 & 99.4 & 78.93 & 53.29 & 35.93 & 20.35 & 8.25 & 4.68 & 2.65 \\
\hline 20 & 171.13 & 119.86 & 96.78 & 66.72 & 45.77 & 25.64 & 10.2 & 5.68 & 3.15 \\
\hline 50 & 184.94 & 132.5 & 108.03 & 75.23 & 52 & 29 & 11.43 & 6.3 & 3.45 \\
\hline 100 & 194.64 & 141.8 & 116.43 & 81.6 & 56.67 & 31.51 & 12.36 & 6.76 & 3.67 \\
\hline
\end{tabular}

(B) Period of 2050s

\begin{tabular}{|c|c|c|c|c|c|c|c|c|c|}
\hline Return & \multicolumn{9}{|c|}{ Duration $(\mathrm{min}): \mathrm{mm} / \mathrm{h}$} \\
\hline Period & 5 & 10 & 15 & 30 & 60 & 120 & 360 & 720 & 1440 \\
\hline & 128.88 & 84.25 & 65.82 & 43.24 & 28.44 & 16.37 & 6.83 & 3.93 & 2.27 \\
\hline & 157.94 & 105.8 & 83.66 & 55.99 & 37.45 & 21.32 & 8.73 & 4.97 & 2.83 \\
\hline
\end{tabular}




\begin{tabular}{rrrrrrrrrr}
20 & 188.13 & 130.59 & 105 & 71.98 & 49.14 & 27.62 & 11.04 & 6.18 & 3.44 \\
50 & 203.67 & 144.64 & 117.53 & 81.81 & 56.55 & 31.53 & 12.42 & 6.87 & 3.78 \\
100 & 213.79 & 154.4 & 126.46 & 89.01 & 62.1 & 34.43 & 13.42 & 7.36 & 4.01 \\
\hline
\end{tabular}

(C) Period of $2080 \mathrm{~s}$

\begin{tabular}{|c|c|c|c|c|c|c|c|c|c|}
\hline \multirow{2}{*}{$\begin{array}{l}\text { Return } \\
\text { Period }\end{array}$} & \multicolumn{9}{|c|}{ Duration (min): $\mathrm{mm} / \mathrm{h}$} \\
\hline & 5 & 10 & 15 & 30 & 60 & 120 & 360 & 720 & 1440 \\
\hline 2 & 133.7 & 87.32 & 68.26 & 44.89 & 29.64 & 17.01 & 7.08 & 4.08 & 2.35 \\
\hline 5 & 153.61 & 103.64 & 82.27 & 55.37 & 37.35 & 21.15 & 8.6 & 4.88 & 2.76 \\
\hline 20 & 174.37 & 123.28 & 99.76 & 68.97 & 47.37 & 26.52 & 10.52 & 5.85 & 3.23 \\
\hline 50 & 185.09 & 134.88 & 110.45 & 77.58 & 53.71 & 29.92 & 11.71 & 6.43 & 3.5 \\
\hline 100 & 192.1 & 143.17 & 118.26 & 84.03 & 58.47 & 32.47 & 12.59 & 6.85 & 3.68 \\
\hline
\end{tabular}

352 Table 9. Numerical IDF curves of AMP estimated by SDExtreme based on scaling GEV model under RCP 8.5 climate 353 change scenario by CanRCM4 for Ottawa rain gauge station.

(A) Period of 2020s

\begin{tabular}{|c|c|c|c|c|c|c|c|c|c|}
\hline \multirow{2}{*}{$\begin{array}{l}\text { Return } \\
\text { Period } \\
\end{array}$} & \multicolumn{9}{|c|}{ Duration (min): $\mathrm{mm} / \mathrm{h}$} \\
\hline & 5 & 10 & 15 & 30 & 60 & 120 & 360 & 720 & 1440 \\
\hline 2 & 127.64 & 83.1 & 64.81 & 42.48 & 27.9 & 16.07 & 6.72 & 3.88 & 2.24 \\
\hline 5 & 156.57 & 104.85 & 82.86 & 55.37 & 36.99 & 21.08 & 8.64 & 4.92 & 2.8 \\
\hline 20 & 183.17 & 127.9 & 103.04 & 70.77 & 48.36 & 27.16 & 10.84 & 6.05 & 3.37 \\
\hline 50 & 195.37 & 139.99 & 114.17 & 79.8 & 55.31 & 30.79 & 12.09 & 6.66 & 3.65 \\
\hline 100 & 202.72 & 147.97 & 121.77 & 86.22 & 60.41 & 33.4 & 12.95 & 7.07 & 3.83 \\
\hline
\end{tabular}

(B) Period of 2050s

\begin{tabular}{|c|c|c|c|c|c|c|c|c|c|}
\hline \multirow{2}{*}{$\begin{array}{l}\text { Return } \\
\text { Period }\end{array}$} & \multicolumn{9}{|c|}{ Duration (min): $\mathrm{mm} / \mathrm{h}$} \\
\hline & 5 & 10 & 15 & 30 & 60 & 120 & 360 & 720 & 1440 \\
\hline 2 & 145.23 & 93.83 & 72.93 & 47.61 & 31.2 & 18 & 7.55 & 4.37 & 2.54 \\
\hline 5 & 171.59 & 115.7 & 91.54 & 61.2 & 40.88 & 23.3 & 9.55 & 5.43 & 3.09 \\
\hline 20 & 190.1 & 135.56 & 110.04 & 76.21 & 52.33 & 29.31 & 11.62 & 6.44 & 3.54 \\
\hline 50 & 196.63 & 144.54 & 119.19 & 84.39 & 58.98 & 32.67 & 12.68 & 6.91 & 3.73 \\
\hline 100 & 199.94 & 149.91 & 124.99 & 89.94 & 63.68 & 34.98 & 13.37 & 7.2 & 3.84 \\
\hline
\end{tabular}

(C) Period of $2080 \mathrm{~s}$

\begin{tabular}{|c|c|c|c|c|c|c|c|c|c|}
\hline \multirow{2}{*}{$\begin{array}{l}\text { Return } \\
\text { Period }\end{array}$} & \multicolumn{9}{|c|}{ Duration $(\mathrm{min}): \mathrm{mm} / \mathrm{h}$} \\
\hline & 5 & 10 & 15 & 30 & 60 & 120 & 360 & 720 & 1440 \\
\hline 2 & 142.17 & 91.67 & 71.36 & 46.73 & 30.69 & 17.68 & 7.39 & 4.27 & 2.48 \\
\hline 5 & 162.19 & 109.61 & 86.82 & 58.23 & 39.02 & 22.19 & 9.07 & 5.15 & 2.92 \\
\hline 20 & 176.54 & 127.56 & 103.72 & 71.93 & 49.47 & 27.68 & 10.96 & 6.06 & 3.32 \\
\hline 50 & 181.71 & 136.48 & 112.84 & 79.95 & 55.89 & 30.95 & 12.01 & 6.53 & 3.5 \\
\hline 100 & 184.36 & 142.15 & 118.98 & 85.66 & 60.6 & 33.31 & 12.73 & 6.84 & 3.61 \\
\hline
\end{tabular}




\subsection{Construct confidence intervals}

SDExtreme was used to construct CIs of AMPs for the present and the future periods. The

358 modified bootstrap technique introduced by Yeo et al. (2020) was used to generate 1,000 sets of

359 AMPs for a duration of 1-day using observed and synthesized daily AMPs by SDRain and quantile

360 mapping with the three climate change scenarios by CanESM2 and CanRCM4. The significance

361 level was set up as 0.05 for constructing the $95 \%$ CIs in this study. The Grey shade represents the

362 range of CIs illustrating at the selected significance level and the black lines are the estimated IDF

363 curves. CIs were constructed by not using historical records in order to evaluate the performance

364 of SDExtreme CI methods. As shown in Figure 10, all observed values fall into the CI ranges for

365 both durations of 5-min and 30-min. This implies that SDExtreme could provide robust CIs of

366 extreme rainfall values without the observed sub-daily and sub-hourly AMPs. Once the CIs

367 method with the historical records weas verified, SDExtreme constructed CIs for IDF curves for

368 the period of 2080s, estimated under four climate change scenarios (i.e. CanESM2 RCP $4.5 \& 8.5$

369 and CanRCM4 RCP $4.5 \& 8.5$ ), corresponding to the 50-year return period. As shown in Figure

37011 , it was found that the range of CIs for RCP 8.5 is quite thinner than those for other climate

371 change scenarios. In addition, the ranges given by CanRCM4 are thinner than those by CanESM2

372 scenarios. Because the thin CIs implies low variability of the estimated AMPs, the result could

373 imply that a significant increase in the extreme rainfall is highly likely under RCP 8.5 climate

374 change scenario. 


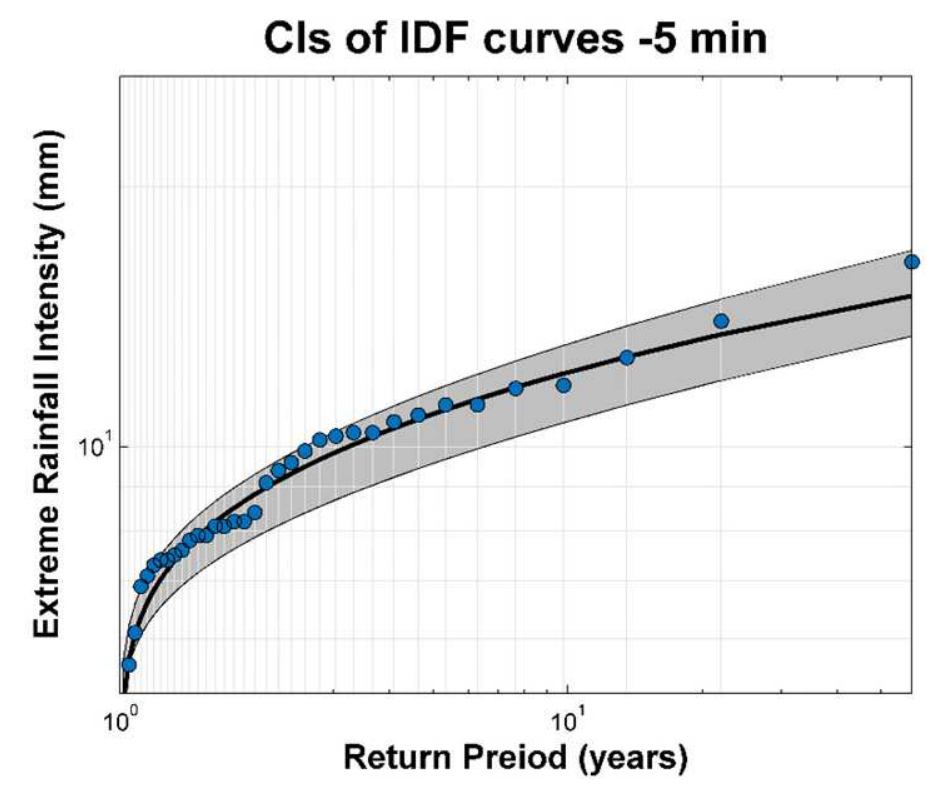

(A)

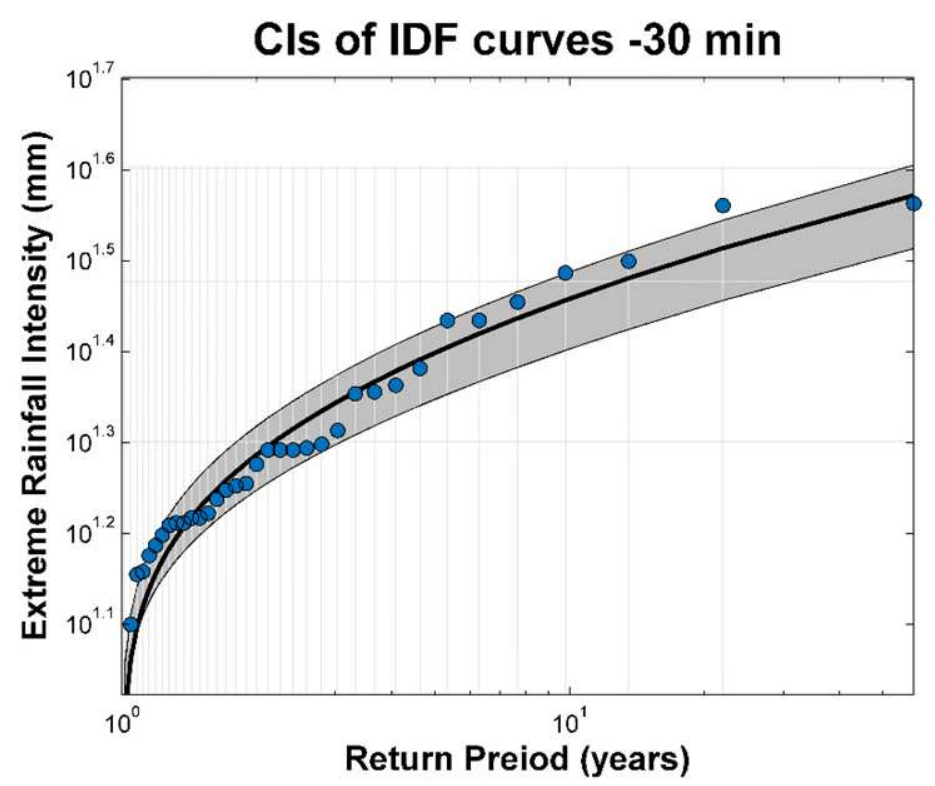

(B)

Figure 10. The 95\% confidence intervals (CIs) of (A) IDF curves for the 5-min duration and (B) 30-min duration for Ottawa rain gauge station, respectively. Grey shade regions are the $90 \%$ CIs constructed by SDExtreme, black lines are the estimated IDF curves, and blue dots represent observed values. 


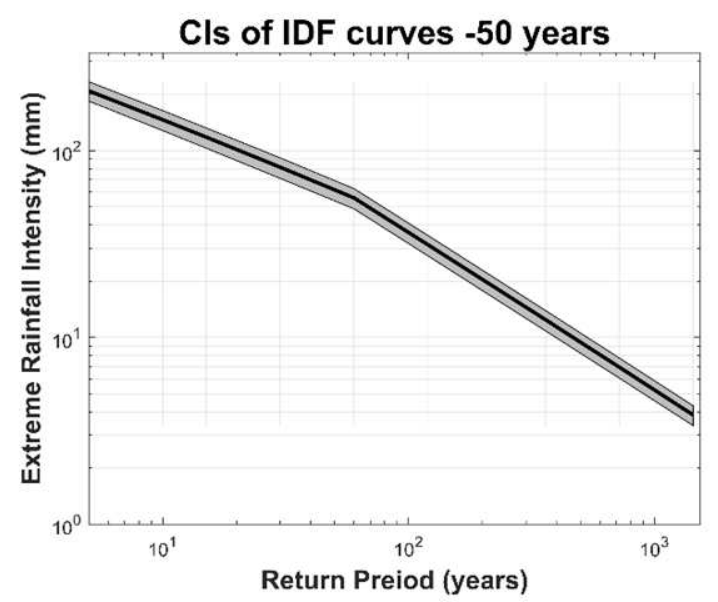

(A)

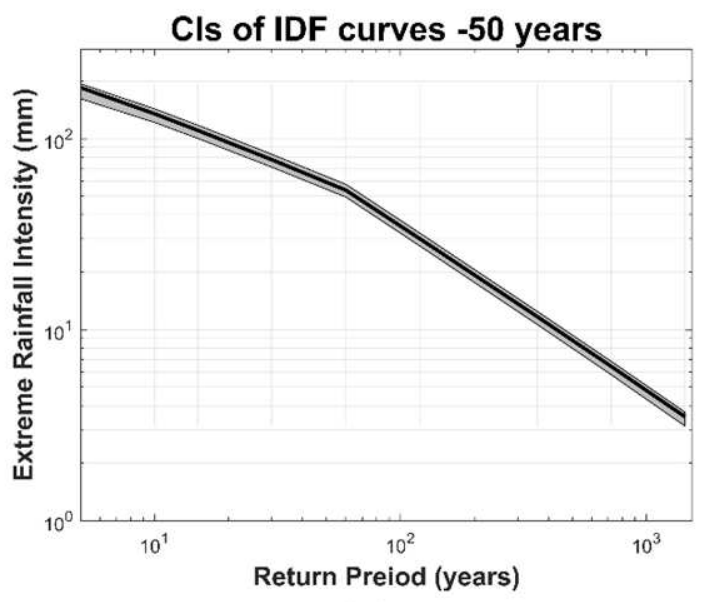

(C)

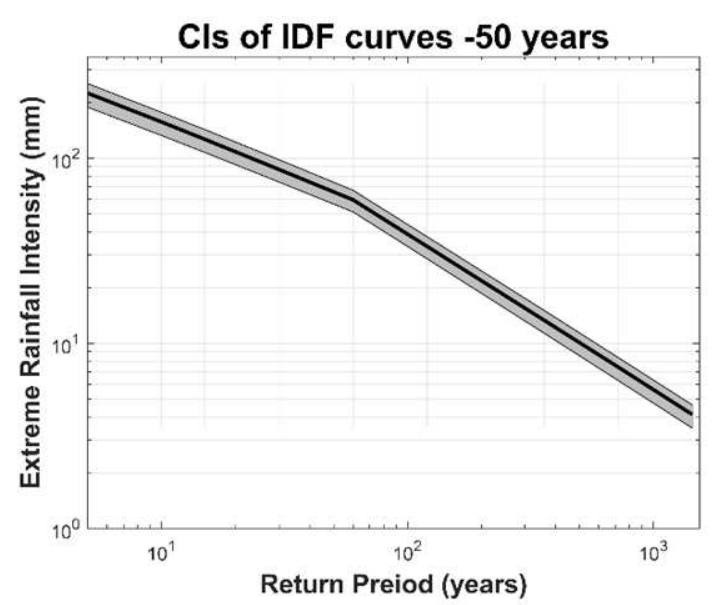

(B)

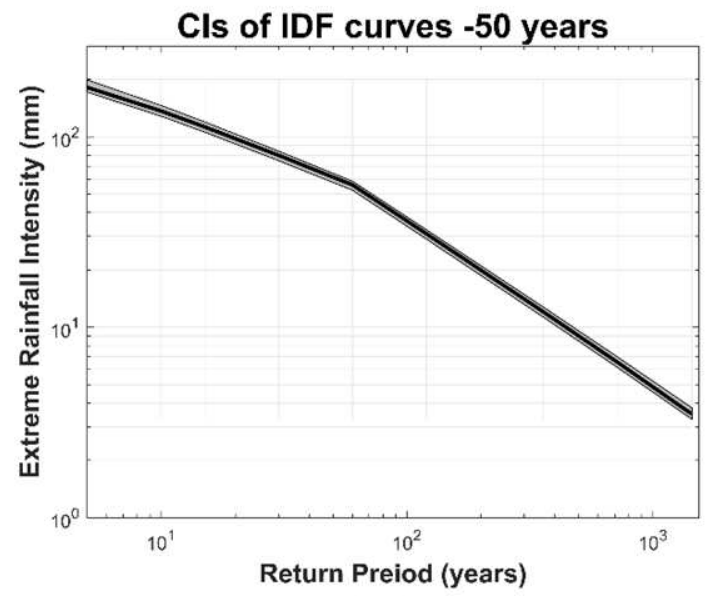

(D)

Figure 11. The 95\% confidence intervals (CIs) for IDF curves (for the period of 2080s) corresponding to 50-year return periods estimated under two greenhouse gases emission scenarios (RCP 4.5, and RCP 8.5) given by CanESM2 and two (RCP 4.5 and RCP 8.5) by CanRCM4, respectively. (A) under RCP 4.5 by CanESM2, (B) under RCP 5.5 by CanESM2, and (C) under RCP 4.5 by CanRCM4, and (D) under RCP 8.5 by CanRCM4. Grey shade regions are the $95 \%$ CIs and black lines are the estimated IDF curves by SDExtreme. 


\section{Conclusions}

An integrated extreme rainfall modeling software package (SDExtreme Version 2.0) was

390 proposed in this study to describe the linkage between different time durations and to construct the

391 CIs for the estimated IDF curves. The feasibility and accuracy of this modeling tool have been

392 tested using climate simulation outputs from CanESM2 and CanRCM4 under three different

393 greenhouse gase emission scenarios and using available AMP series for durations ranging form 5

394 minutes to 1 day at 16 stations located in southern Quebec and Ontario provinces (Canada) over

395 the period of 1961-1990. It is found that the AMP series at all stations displayed a simple scaling

396 behavior within two different time intervals. Based on this scaling property, the scaling GEV

397 distribution has been shown to be able to provide accurate estimates of sub-daily AMPs from

398 observed and GCM-downscaled daily AMP amounts. Therefore, it can be concluded that it is

399 feasible to use SDExtreme to describe the relationship between large-scale climate predictors for

400 daily scale given by GCM and RCM simulation outputs and the daily and sub-daily AMPs at a

401 local site.

Furthermore, the proposed assessment tool was implemented to construct the IDF relations

403 for a given site for the 1961-1990 period and the future periods (2020s, 2050s, and 2080s) using

404 climate predictors given by CanESM2 and CanRCM4 simulations. Results show the significant

405 increasing trend in daily AMPs for the future periods. The highest increase in extreme rainfall was

406 observed in the estimated by RCP 8.5 scenario given by CanESM2.

SDExtreme software package provides the CIs using only daily AMP series and simple

409 AMPs as well as the observed value for the uncertainty study. It was found that the CIs vary with 410 respect to climate change scenarios. 


\section{Declarations}

\section{$412 \quad$ Funding}

413 The development of SDExtreme was supported by FloodNet-NSERC (National Sciences

414 and Engineering Research Council of Canada) from November 2014 to January 2017. The detailed

415 information about FloodNet-NSERC is available at the website: http://www.nsercfloodnet.ca.

\section{Conflicts of interest/Competing interests}

417 The authors declare that they have no known competing financial interests or personal

418 relationships that could have appeared to influence the work reported in this paper.

\section{Code availability}

420 SDExtreme, example annual maximum precipitation series, and statiscally/dynamically 421 downscaled data sets are available at the Mendeley Dataset

422 (https://data.mendeley.com/datasets/kc9frpgfvs/1). In addition, the main source are compiled by 423 MATLAB 2014a. So, the requirement for running this software is to install MATLAB Runtime

424 version 8.3 (see the website: https://www.mathworks.com/products/compiler/matlab425 runtime.html).

\section{Availability of data and material}

427 The Mendeley Dataset (https://data.mendeley.com/datasets/kc9frpgfvs/1) contains several 428 data sets: historical annual maximum precipitation series and downscalled daily precipitation 429 series. More specifically, here is the detail information;

- Historical annual maximum precipitation series: the three rain gauge stations 
- Downscaled precipitation series: in this study two downscaling methods were implemented for the comparison purpose. For staitsitcal downscaling model, SDRain (Yeo et al., 2019) was used for spatially downscaling CanESM2 model with three greenhouse gas emission scenarios (RCP2.6, RCP4.5, and RCP8.5). The file names are CanESM2_R**_Ottawa. OUT. For dynamical downscaling model, CanRCM4 is used. Because of low value events, an additional statistical procedure (quantile mapping) was used. The file names are

\section{$441 \quad$ Ethics approval}

Approved.

\section{Consent to participate}

444 Yeo, Myeong-Ho: Theoretical parts, Development of source codes and software,

445 Methodology and Applications, Data analyses, Writing - Original draft

446 Van-Thanh-Van Nguyen: Writing - review \& editing

$447 \quad$ Yong Sang Kim: Writing - review \& editing

448 Theodore A. Kpodonu: Writing - review \& editing.

\section{Consent for publication}

All authors are consent. 


\section{Reference}

454 BOUGADIS, J. \& ADAMOWSKI, K. 2006. Scaling model of a rainfall intensity-durationfrequency relationship. Hydrological processes, 20, 3747-3757.

BUISHAND, T. 1989. Statistics of extremes in climatology. Statistica Neerlandica, 43, 1-30.

CHANG, C. \& HIONG, S. Estimation of sub-daily IDF curves in Singapore using simple scaling. International conference on climate change effects, 2013. 221-230.

GUPTA, V. K. \& WAYMIRE, E. 1990. Multiscaling properties of spatial rainfall and river flow distributions. Journal of Geophysical Research: Atmospheres, 95, 1999-2009.

IPCC 2014. Climate change 2014: synthesis report. Contribution of Working Groups I, II and III to the fifth assessment report of the Intergovernmental Panel on Climate Change, IPCC.

KALNAY, E., KANAMITSU, M., KISTLER, R., COLLINS, W., DEAVEN, D., GANDIN, L., IREDELL, M., SAHA, S., WHITE, G. \& WOOLLEN, J. 1996. The NCEP/NCAR 40-year reanalysis project. Bulletin of the American meteorological Society, 77, 437-472.

KOZANIS, S., CHRISTOFIDES, A., MAMASSIS, N., EFSTRATIADIS, A. \& KOUTSOYIANNIS, D. 2010. Hydrognomon-open source software for the analysis of hydrological data. European Geophysical Union General Assembly 2010.

LIEW, S. C., RAGHAVAN, S. V. \& LIONG, S.-Y. 2014. Development of Intensity-DurationFrequency curves at ungauged sites: risk management under changing climate. Geoscience Letters, $1,8$.

HydroCAD Software Solutions, LLC. 2015. "HydroCAD Stormwater Modeling." Accessed 30 August 2016. http://www.hydrocad.net/

NGUYEN, V.-T.-V., NGUYEN, T.-D. \& CUNG, A. 2007. A statistical approach to downscaling of sub-daily extreme rainfall processes for climate-related impact studies in urban areas. Water science and technology: water supply, 7, 183-192.

NGUYEN, V., DESRAMAUT, N. \& NGUYEN, T. Estimation of urban design storms in consideration of GCM-based climate change scenarios. Proc. of International Conference on Water \& Urban Development Paradigms: Towards an integration of engineering, design and management approaches, Leuven, 2008. 347-356.

NGUYEN, V., NGUYEN, T.-D. \& ASHKAR, F. 2002. Regional frequency analysis of extreme rainfalls. Water science and technology, 45, 75-81.

NHAT, L. M., TACHIKAWA, Y., SAYAMA, T. \& TAKARA, K. 2007. A simple scaling charateristics of rainfall in time and space to derive intensity duration frequency relationships. Proceedings of Hydraulic Engineering, 51, 73-78.

OMBADI, M., NGUYEN, P., SOROOSHIAN, S. \& HSU, K. L. 2018. Developing IntensityDuration-Frequency (IDF) Curves From Satellite-Based Precipitation: Methodology and Evaluation. Water Resources Research, 54, 7752-7766.

OUALI, D. \& CANNON, A. 2018. Estimation of rainfall intensity-duration-frequency curves at ungauged locations using quantile regression methods. Stochastic Environmental Research and Risk Assessment, 32, 2821-2836.

PIZARRO, R., INGRAM, B., GONZALEZ-LEIVA, F., VALDÉS-PINEDA, R., SANGÜESA, C., DELGADO, N., GARCÍA-CHEVESICH, P. \& VALDÉS, J. B. 2018. WEBSEIDF: A Web-Based System for the Estimation of IDF Curves in Central Chile. Hydrology, 5, 40.

RODRÍGUEZ, R., NAVARRO, X., CASAS, M. C., RIBALAYGUA, J., RUSSO, B., POUGET, L. \& REDAÑO, A. 2014. Influence of climate change on IDF curves for the metropolitan area of Barcelona (Spain). International journal of climatology, 34, 643-654. 
SIMONOVIC, S. P., SCHARDONG, A., SANDINK, D. \& SRIVASTAV, R. 2016. A web-based tool for the development of intensity duration frequency curves under changing climate. Environmental modelling \& software, 81, 136-153.

VU, M., RAGHAVAN, S., LIU, J. \& LIONG, S. Y. 2018. Constructing short-duration IDF curves using coupled dynamical-statistical approach to assess climate change impacts. international Journal of Climatology, 38, 2662-2671.

WILKS, D. S. 1993. Comparison of three-parameter probability distributions for representing annual extreme and partial duration precipitation series. Water Resources Research, 29, 3543-3549.

YEO, M.-H. 2014. Statistical modeling of precipitation processes for gaged and ungaged sites in the context of climate change. McGill University Libraries.

YEO, M.-H., NGUYEN, H.-L. \& NGUYEN, V.-T.-V. 2019. A Statistical Tool to Modelling of Daily Precipitation Process in the Context of Climate Change. Journal of Water and Climate Change, 1 February 2021; $12 \quad$ (1): 18-31. doi: https://doi.org/10.2166/wcc.2019.403.

YEO, M. H., NGUYEN, V. T. V. \& KPODONU, T. A. 2020. Characterizing extreme rainfalls and constructing Confidence Intervals for IDF curves using Scaling-GEV distribution model. International Journal of Climatology.

YEO, M.H.; Nguyen, V.-T.-V.; Kim, Y.S.; Kpodonu, T. A. (2021), “An Integrated Extreme Rainfall Modeling Tool (SDExtreme) for Climate Change Impacts and Adaptation Datasets", Mendeley Data, V1, doi: 10.17632/kc9frpgfvs.1

ZALINA, M. D., DESA, M. N. M., NGUYEN, V. \& KASSIM, A. H. M. 2002. Selecting a probability distribution for extreme rainfall series in Malaysia. Water science and technology, 45, 63-68. 
526 Table 10. Geographical information of the selected 16 rain gauges.

527 Table 11. Numerical IDF curves (the current period) using the L-moment method and the ThreeNCMs method for Toronto station (Ontario): (A) numerical IDF curves by L-moments method and (B) those by Thee-NCMs method.

Table 12. Numerical IDF curves (the current period) using the L-moment estimation method and the Three-NCMs method for St. Hubert station (Quebec): (A) numerical IDF curves by Lmoments method and (B) those by Thee-NCMs method.

Table 13. Scaling exponents of the third NCMs for the shorter and longer durations, and the durations for the break-points.

Table 14. Numerical IDF curves of AMP estimated by SDExtreme based on scaling GEV model under RCP 2.6 climate change scenario by CanESM2 for Ottawa rain gauge station.

Table 15. Numerical IDF curves of AMP estimated by SDExtreme based on scaling GEV model under RCP 4.5 climate change scenario by CanESM2 for Ottawa rain gauge station.

Table 16. Numerical IDF curves of AMP estimated by SDExtreme based on scaling GEV model under RCP 8.5 climate change scenario by CanESM2 for Ottawa rain gauge station.

Table 17. Numerical IDF curves of AMP estimated by SDExtreme based on scaling GEV model under RCP 4.5 climate change scenario by CanRCM4 for Ottawa rain gauge station.

543 Table 18. Numerical IDF curves of AMP estimated by SDExtreme based on scaling GEV model under RCP 8.5 climate change scenario by CanRCM4 for Ottawa rain gauge station. 
Figure 12. Main menu of SDExtreme.

Figure 13. SDExtreme computational steps.

550

Figure 14. The study area encompasses the southern Quebec and Ontario Provinces (Canada). Red points denote the rain-gauge stations in Quebec Province, and blue circles do the raingauge stations in Ontario Province.

Figure 15. Quantile plots comparing the observed to the estimated values by L-moments method and Three-NCM method for the selected durations (e.g. 5-min and 30-min) at Toronto (Ontario) and St. Hubert (Quebec), respectively. (A) 5-min quantile plot for Dorval, (B) 30-min quantile plot for Toronto, (C) 5-min quantile plot for St. Hubert, and (D) 30-min quantile plot for St. Hubert. The black asterisk represents the observed values, the red line does the quantiles estimated by Three-NCM method, and blue line denotes those by Lmoment method.

Figure 16. Log-log plots of non-central moments (NCMs) of the first three orders against several durations for (A) Toronto and (C) St. Hubert. Blue diamonds denote the first order NCMs, green triangles do the second order NCMs, and red dots represent the third order NCMs. $\mathrm{R}$-square plots are provided for detecting the best case to demonstrate two scaling regimes.

Figure 17. Spatial distributions of scaling exponents for the third NCMs. (A) scaling exponents for the shorter durations and (B) for the longer durations.

Figure 18. Plots of the scaling exponents against the order of NCMs of AMP for (A) Toronto and (B) St. Hubert stations. Blue-diamonds represent the scaling exponents for the shorter duration and red-dots denote those for longer duration.

Figure 19. IDF curves of AMPs for 5-min (or 10-min) and 30-min durations estimated by Lmoments and the simple scaling models for Toronto (A, B) and St. Hubert (C, D), respectively. Blue dots represent the observed rainfall intensities, green diamonds do the estimated

Figure 20. Estimated daily AMPs corresponding to 100-year return period for the current and future periods (2020s, 2050s, and 2080s) for Ottawa station.

Figure 21. The 95\% confidence intervals (CIs) of (A) IDF curves for the 5-min duration and (B) 30-min duration for Ottawa rain gauge station, respectively. Grey shade regions are the $90 \%$ CIs constructed by SDExtreme, black lines are the estimated IDF curves, and blue dots represent observed values.

Figure 22. The 95\% confidence intervals (CIs) for IDF curves (for the period of 2080s) corresponding to 50-year return periods estimated under two greenhouse gases emission scenarios (RCP 4.5, and RCP 8.5) given by CanESM2 and two (RCP 4.5 and RCP 8.5 ) by CanRCM4, respectively. (A) under RCP 4.5 by CanESM2, (B) under RCP 5.5 by CanESM2, and (C) under RCP 4.5 by CanRCM4, and (D) under RCP 8.5 by CanRCM4. 
Grey shade regions are the 95\% CIs and black lines are the estimated IDF curves by 
Figures

\begin{tabular}{|c|c|c|c|c|}
\hline \multicolumn{1}{|l|}{ Statistical Downscaling AMPs Ver.2.0 } & - & $\square$ \\
\hline Intro & $\begin{array}{c}\text { IDF } \\
\text { Current Period }\end{array}$ & $\begin{array}{c}\text { Scaling GEV } \\
\text { Model }\end{array}$ & $\begin{array}{c}\text { IDF } \\
\text { Climate Change }\end{array}$ & $\begin{array}{c}\text { Confidence } \\
\text { Intervals }\end{array}$ \\
\hline
\end{tabular}

\author{
Statistical Donwscaling Model \\ for Extreme Rainfalls \\ Scaling-GEV Distribution
}

Figure 1

Main menu of SDExtreme. 


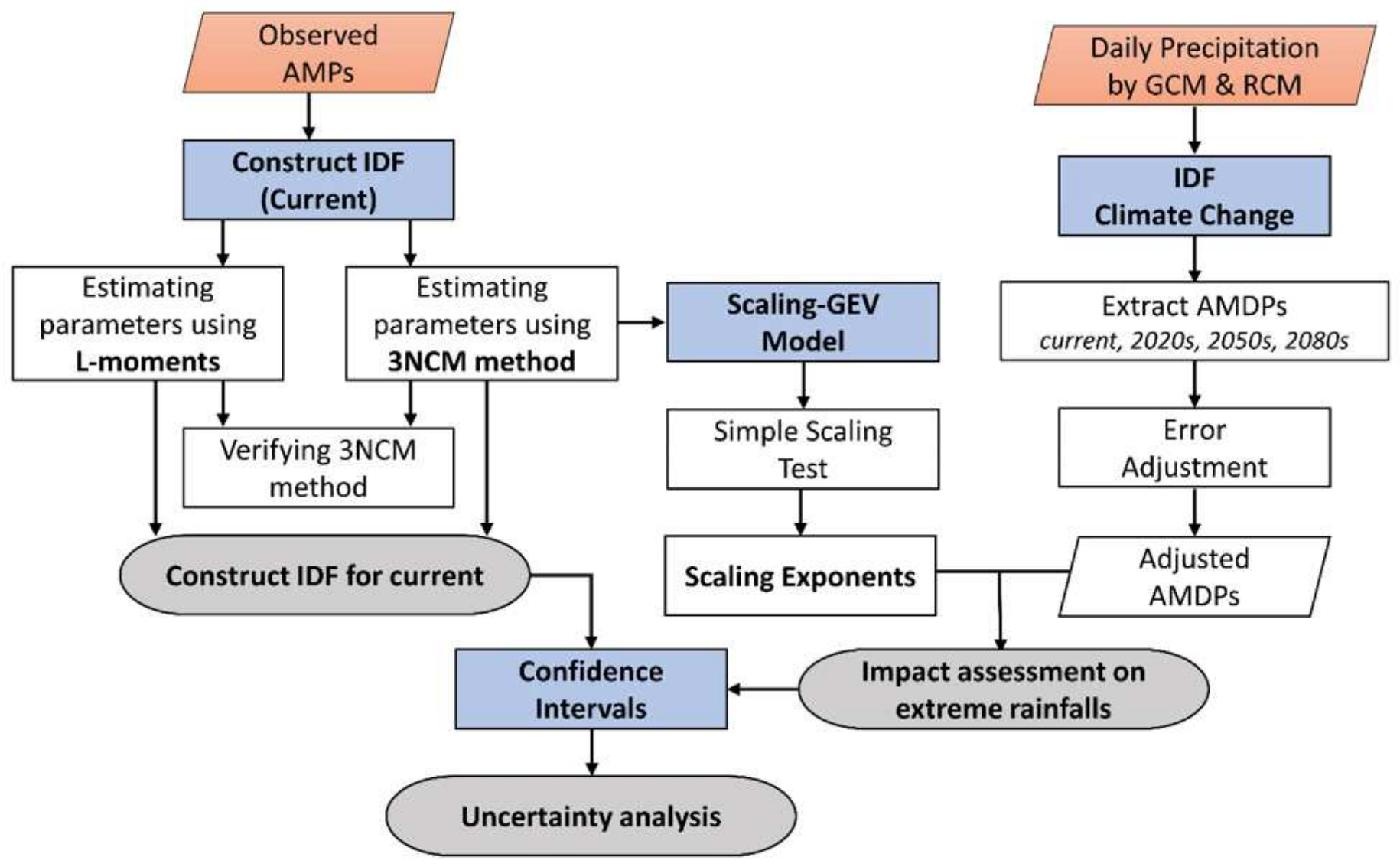

Figure 2

SDExtreme computational steps. 


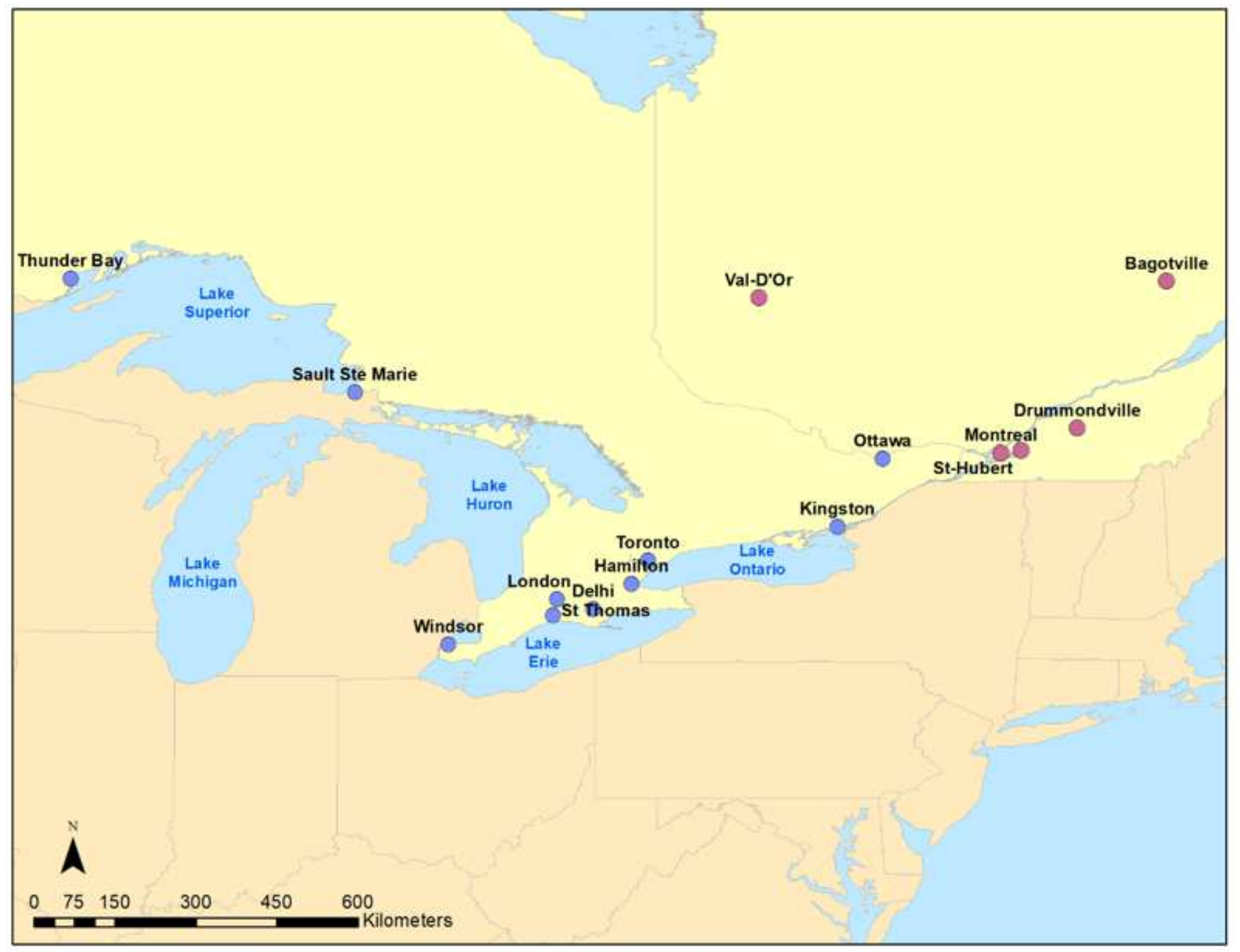

Figure 3

The study area encompasses the southern Quebec and Ontario Provinces (Canada). Red points denote the rain-gauge stations in Quebec Province, and blue circles do the rain-gauge stations in Ontario Province. Note: The designations employed and the presentation of the material on this map do not imply the expression of any opinion whatsoever on the part of Research Square concerning the legal status of any country, territory, city or area or of its authorities, or concerning the delimitation of its frontiers or boundaries. This map has been provided by the authors 


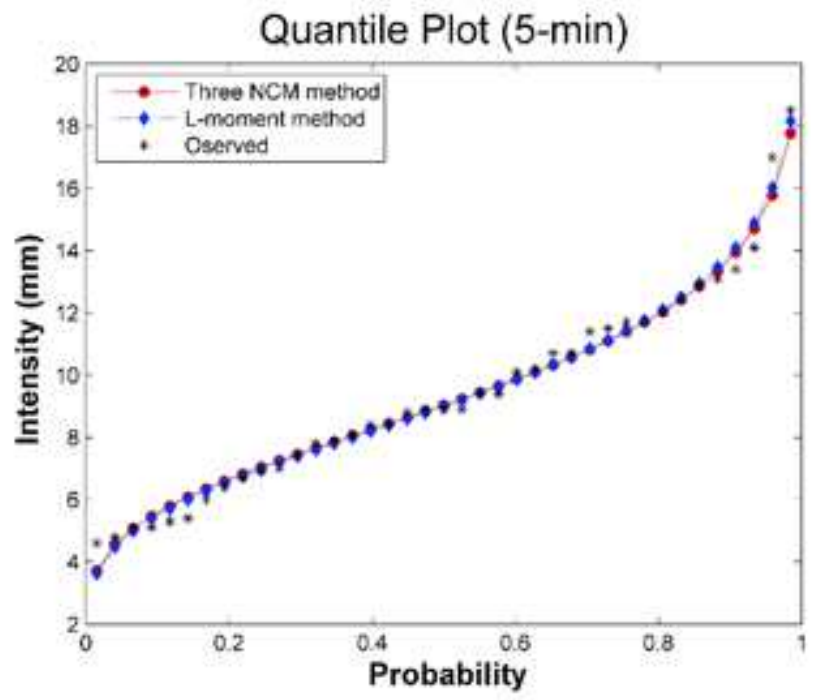

(A)

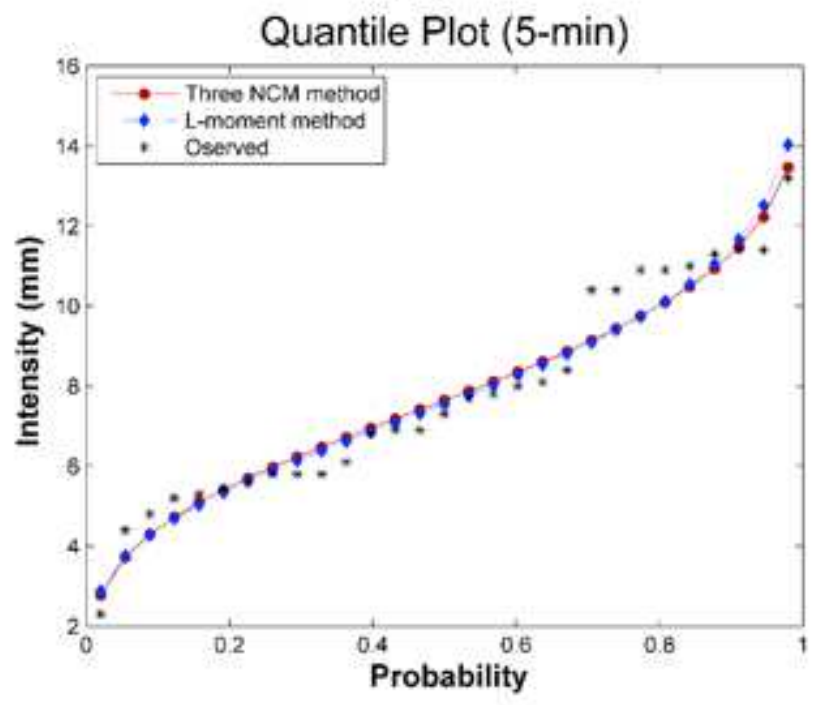

(C)

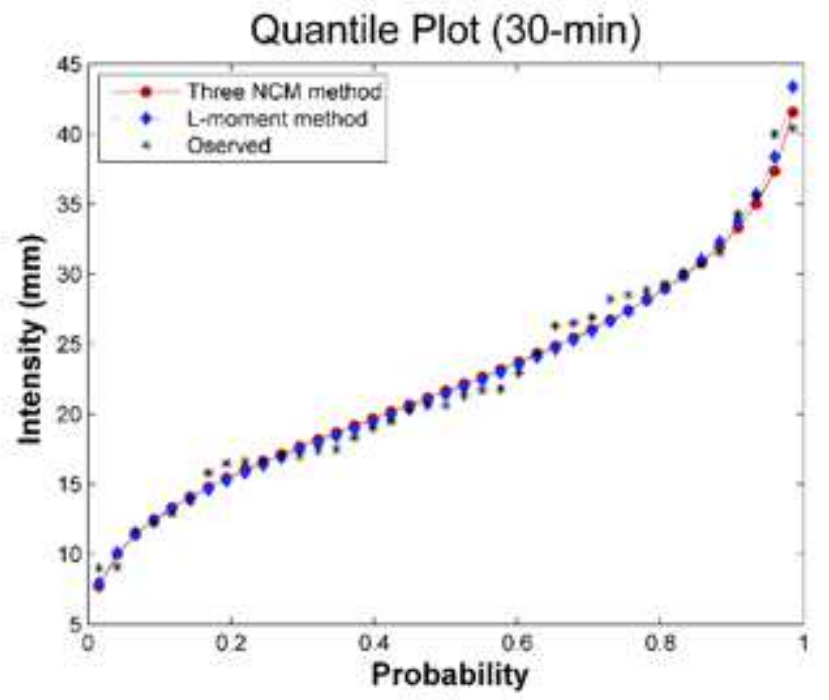

(B)

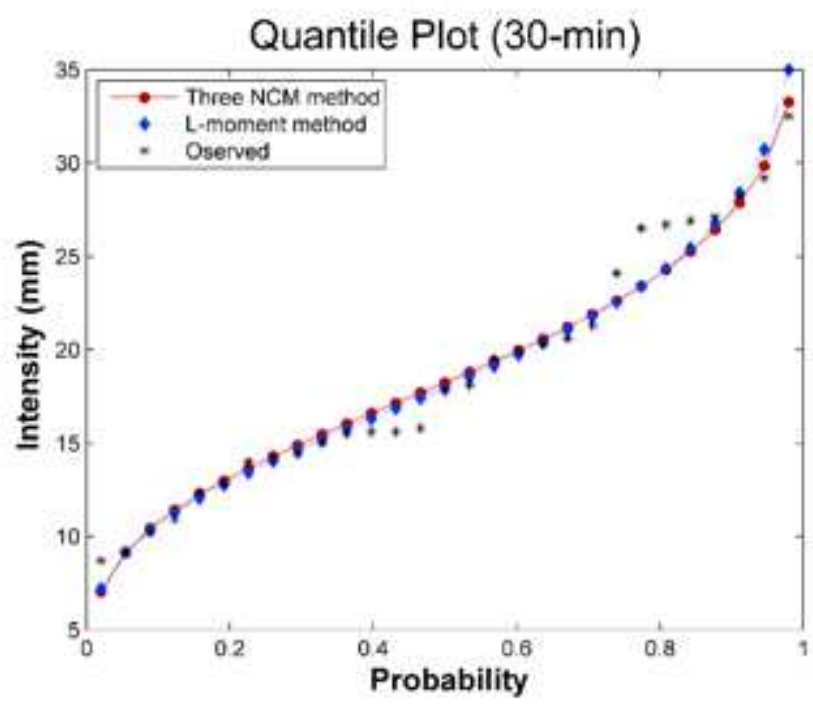

(D)

\section{Figure 4}

Quantile plots comparing the observed to the estimated values by L-moments method and Three-NCM method for the selected durations (e.g. 5-min and 30-min) at Toronto (Ontario) and St. Hubert (Quebec), respectively. (A) 5-min quantile plot for Dorval, (B) 30-min quantile plot for Toronto, (C) 5-min quantile plot for St. Hubert, and (D) 30-min quantile plot for St. Hubert. The black asterisk represents the observed values, the red line does the quantiles estimated by Three-NCM method, and blue line denotes those by Lmoment method. 


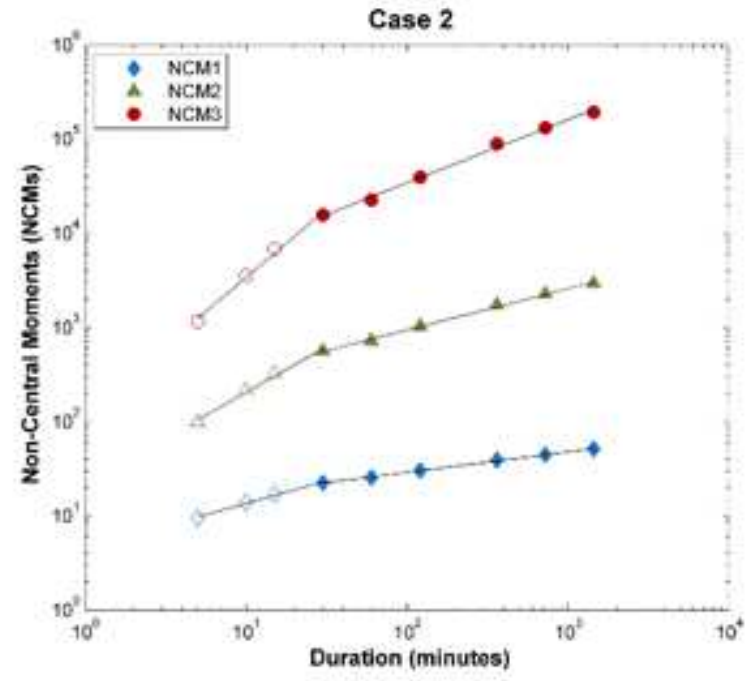

(A)

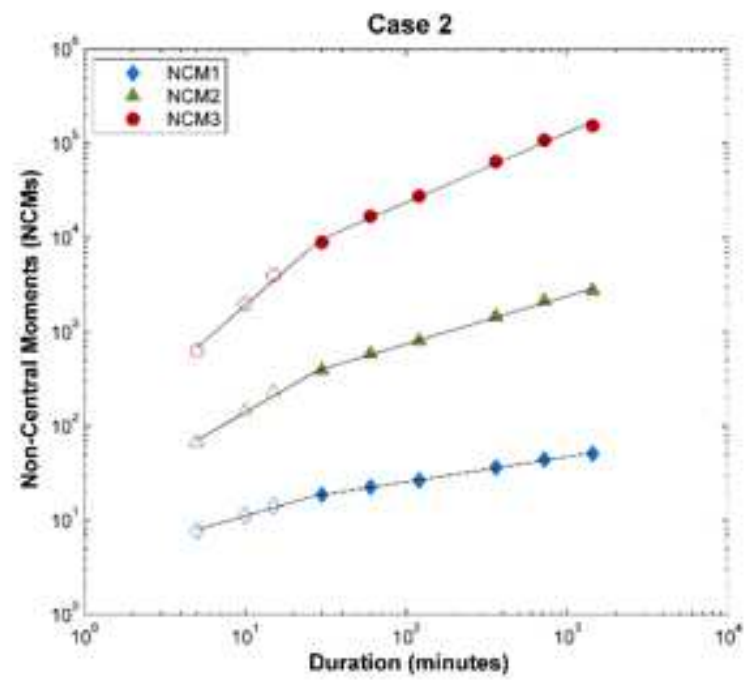

(C)

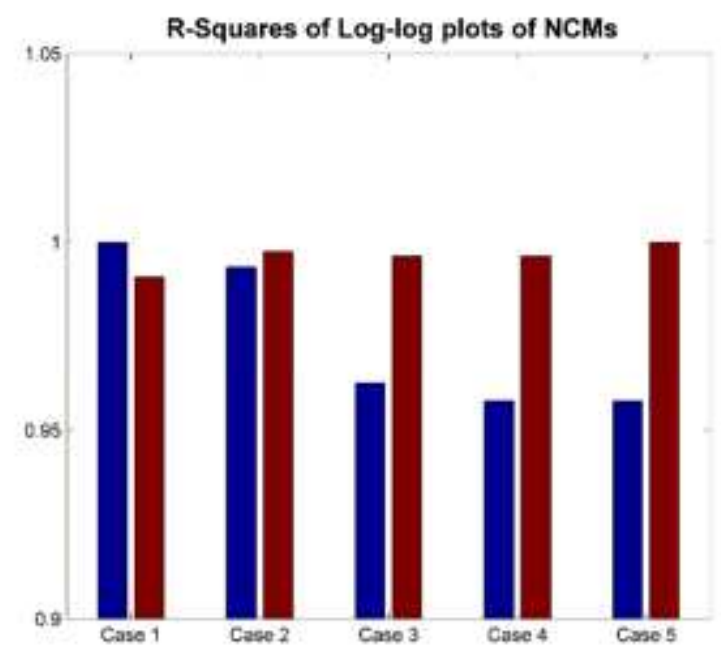

(B)

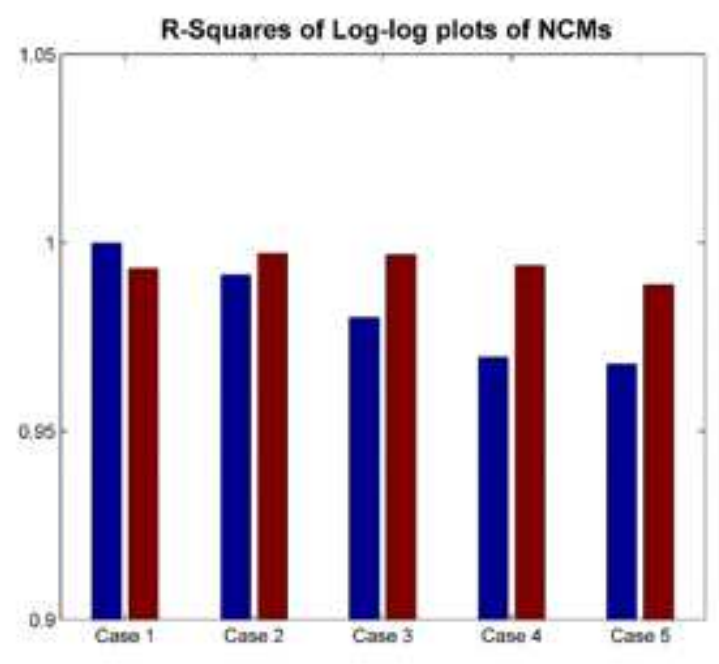

(D)

Figure 5

Log-log plots of non-central moments (NCMs) of the first three orders against several durations for (A) Toronto and (C) St. Hubert. Blue diamonds denote the first order NCMs, green triangles do the second order NCMs, and red dots represent the third order NCMs. R-square plots are provided for detecting the best case to demonstrate two scaling regimes. 


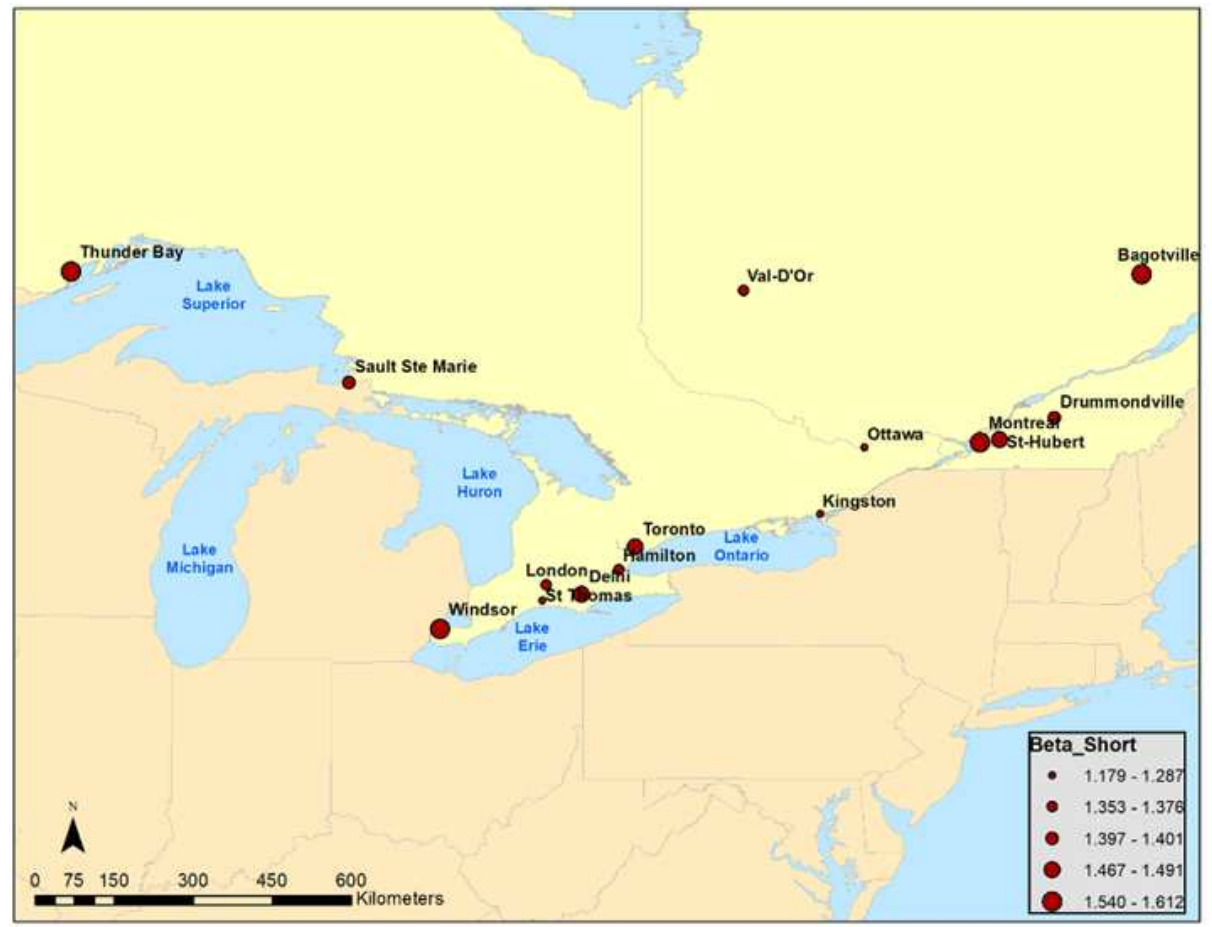

(A)

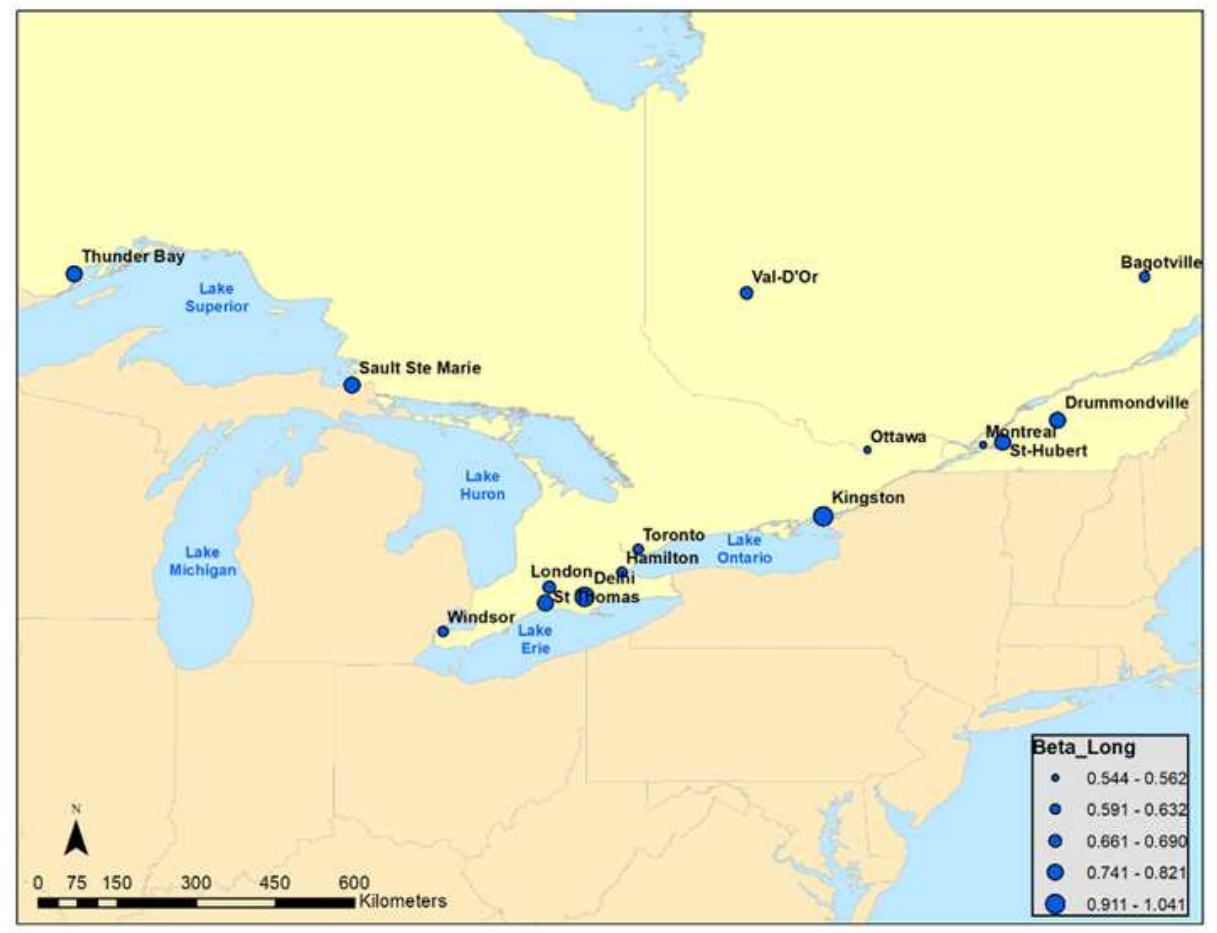

(B)

\section{Figure 6}

Spatial distributions of scaling exponents for the third NCMs. (A) scaling exponents for the shorter durations and $(B)$ for the longer durations. Note: The designations employed and the presentation of the material on this map do not imply the expression of any opinion whatsoever on the part of Research Square concerning the legal status of any country, territory, city or area or of its authorities, or concerning the delimitation of its frontiers or boundaries. This map has been provided by the authors. 


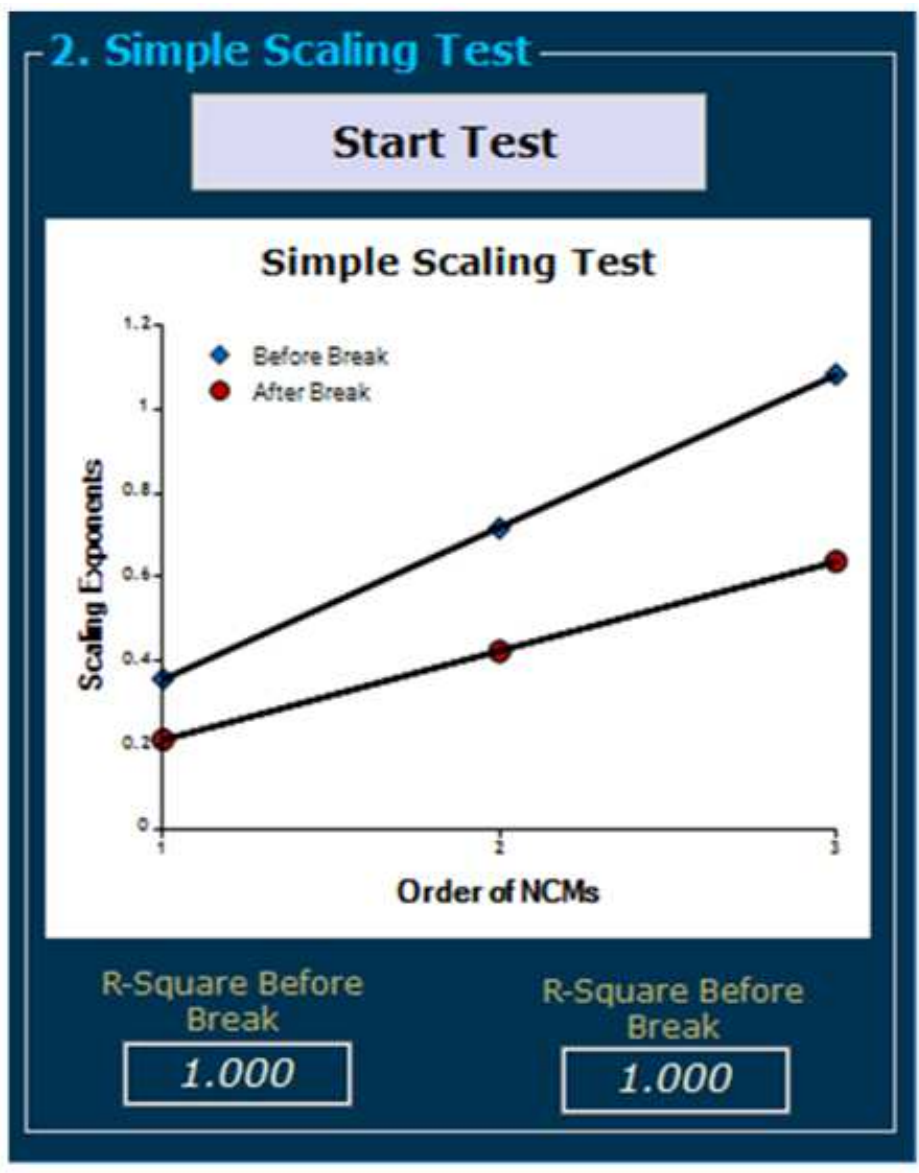

(A)

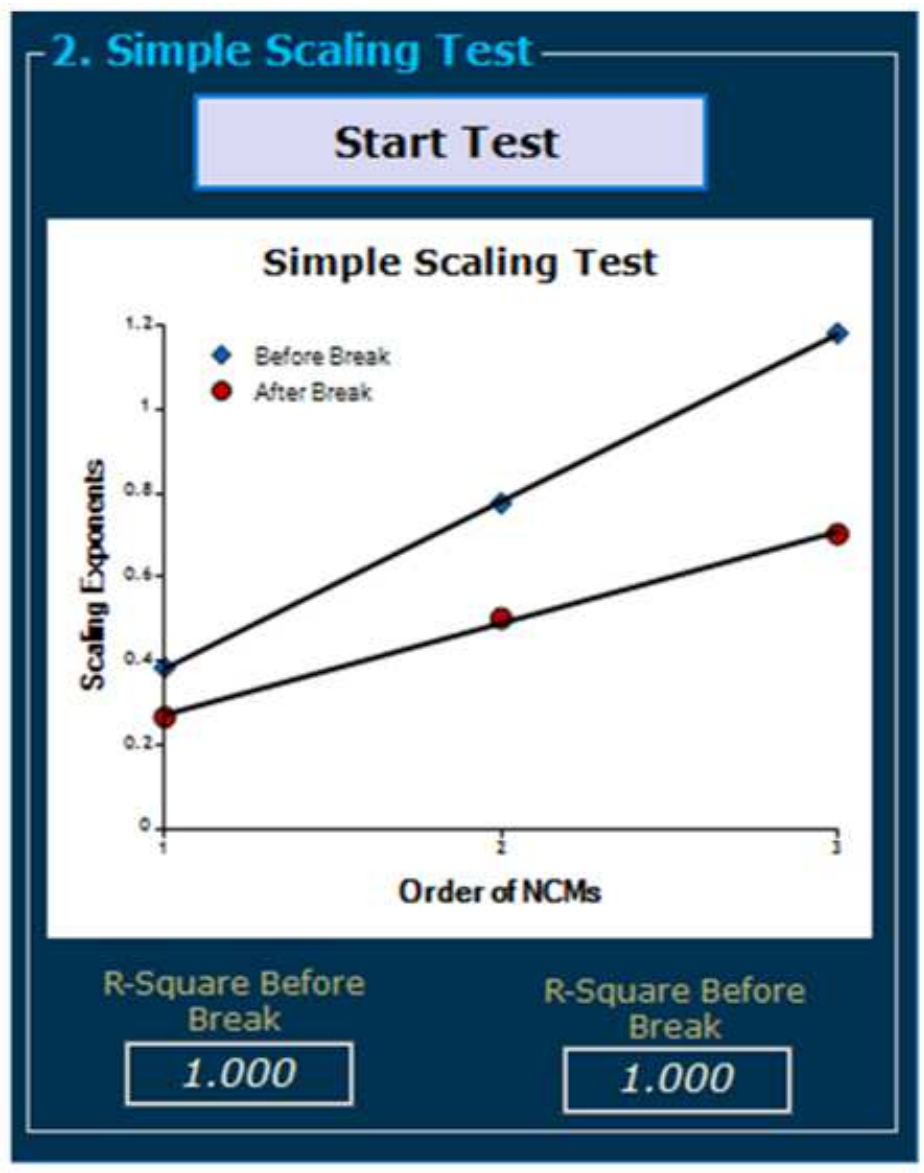

(B)

Figure 7

Plots of the scaling exponents against the order of NCMs of AMP for (A) Toronto and (B) St. Hubert stations. Blue-diamonds represent the scaling exponents for the shorter duration and red-dots denote those for longer duration. 


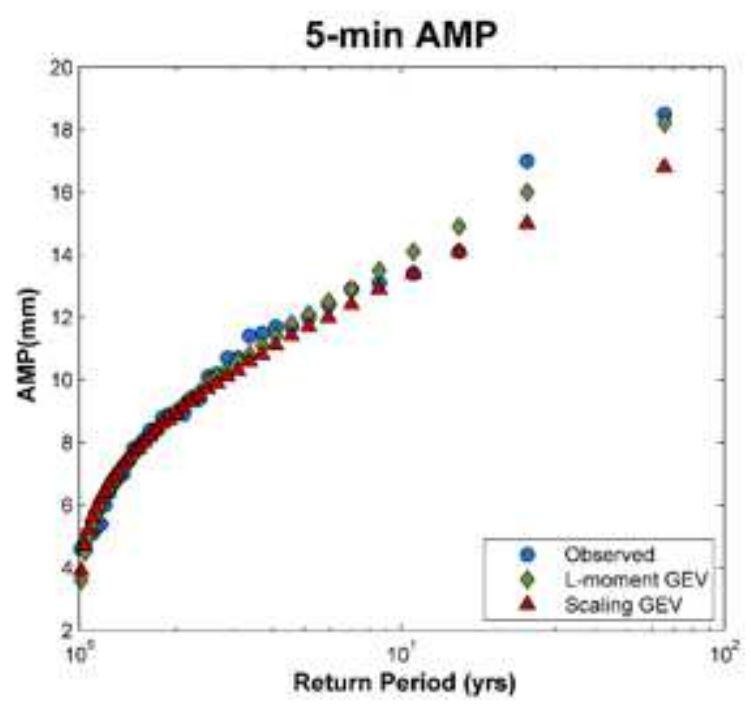

(A)

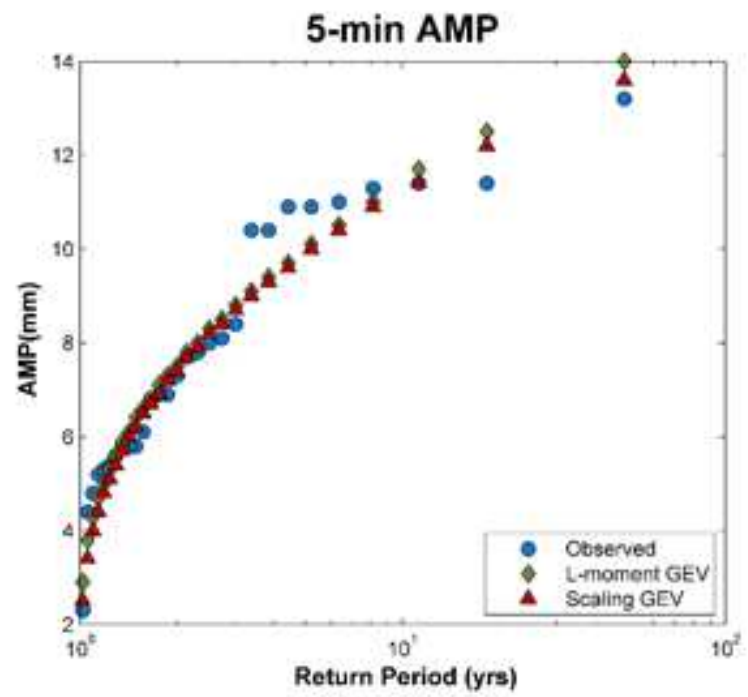

(C)

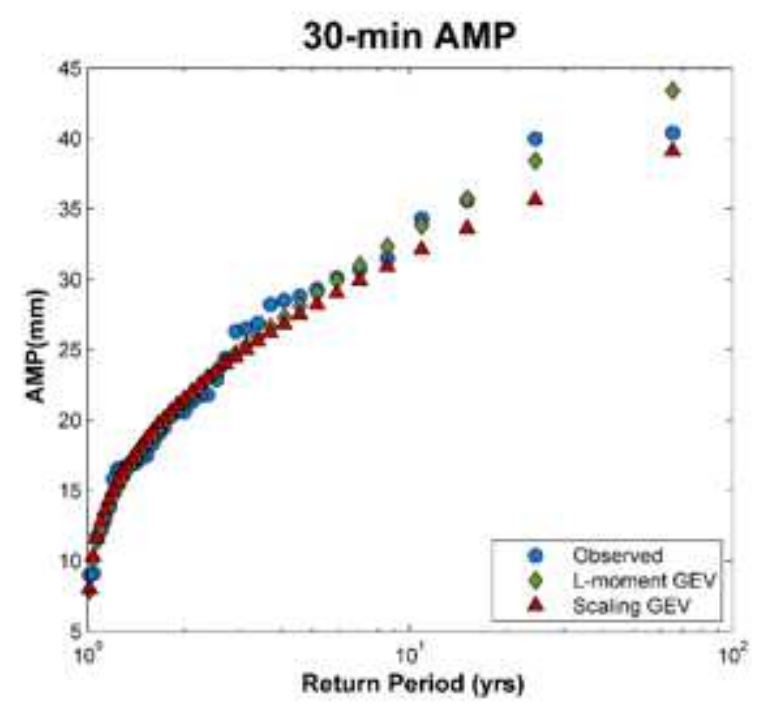

(B)

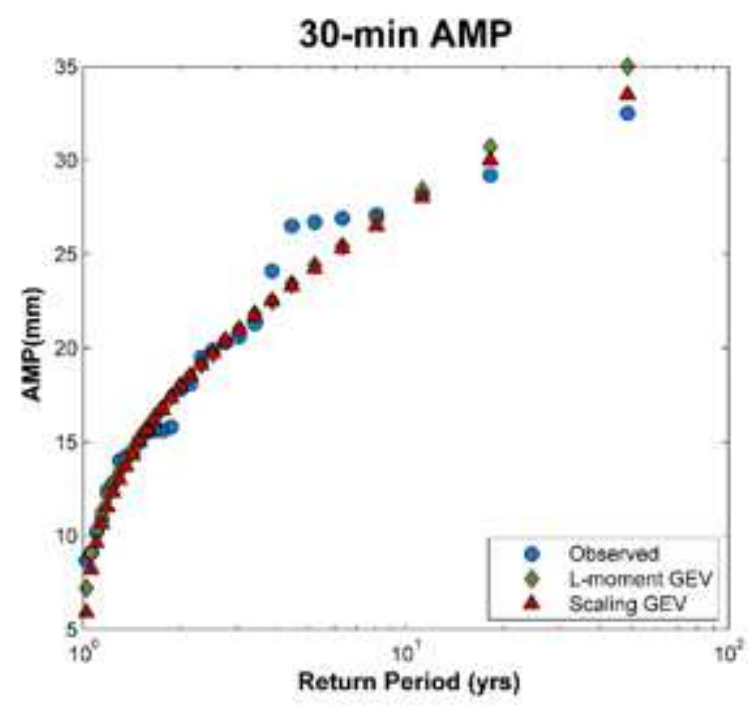

(D)

\section{Figure 8}

IDF curves of AMPs for 5-min (or 10-min) and 30-min durations estimated by L-moments and the simple scaling models for Toronto (A, B) and St. Hubert (C, D), respectively. Blue dots represent the observed rainfall intensities, green diamonds do the estimated 


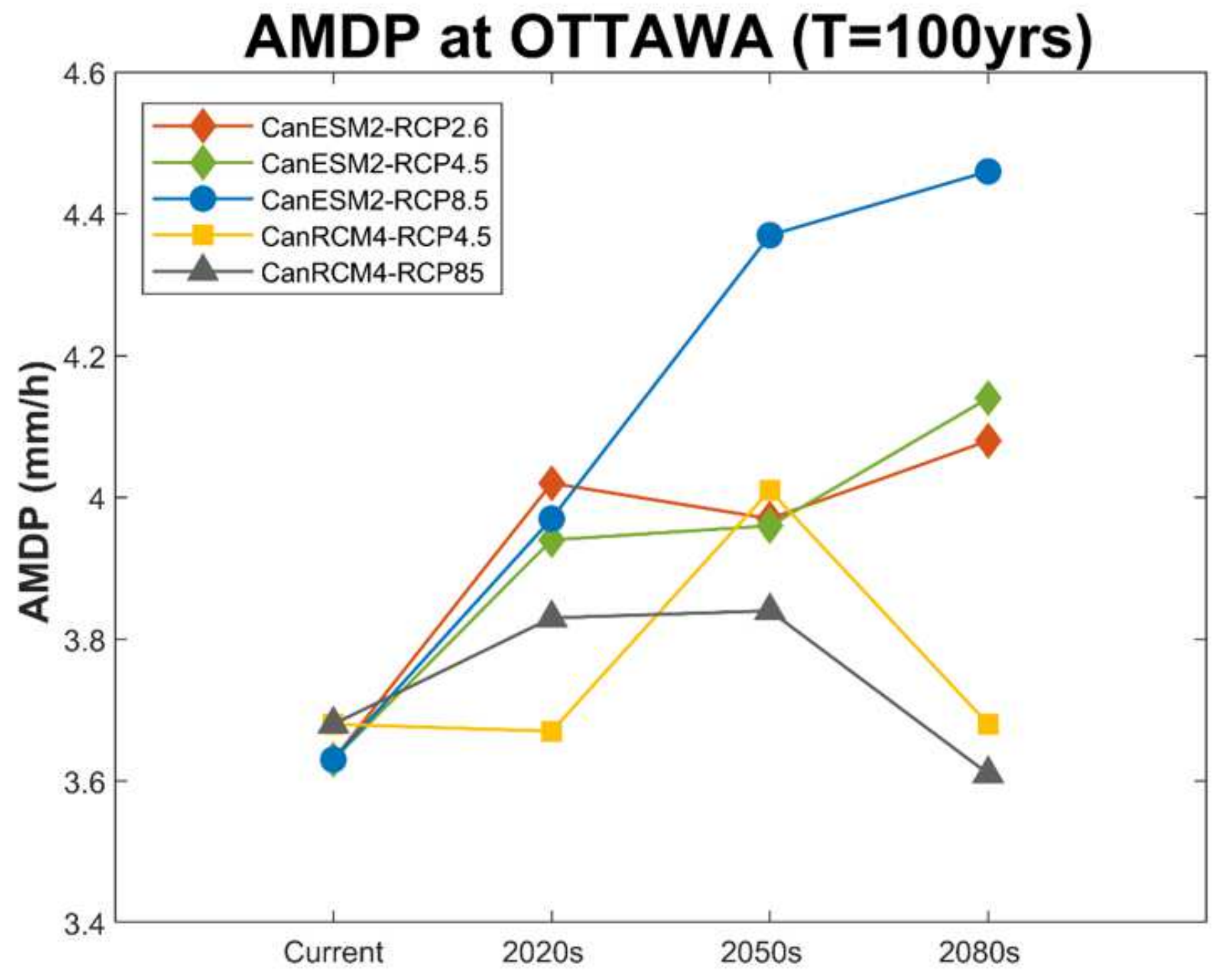

Figure 9

Estimated daily AMPs corresponding to 100-year return period for the current and future periods (2020s, 2050s, and 2080s) for Ottawa station. 


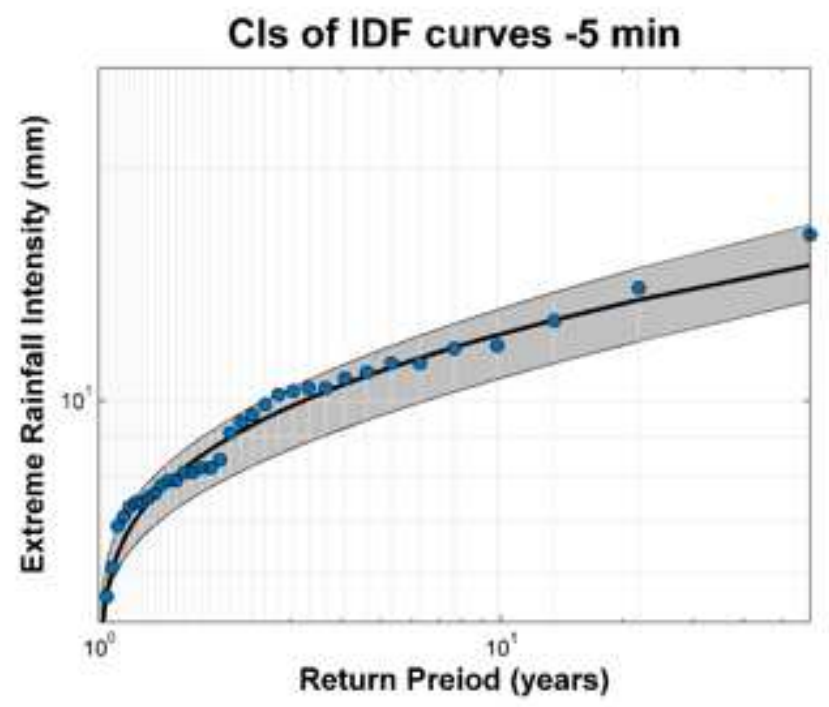

(A)

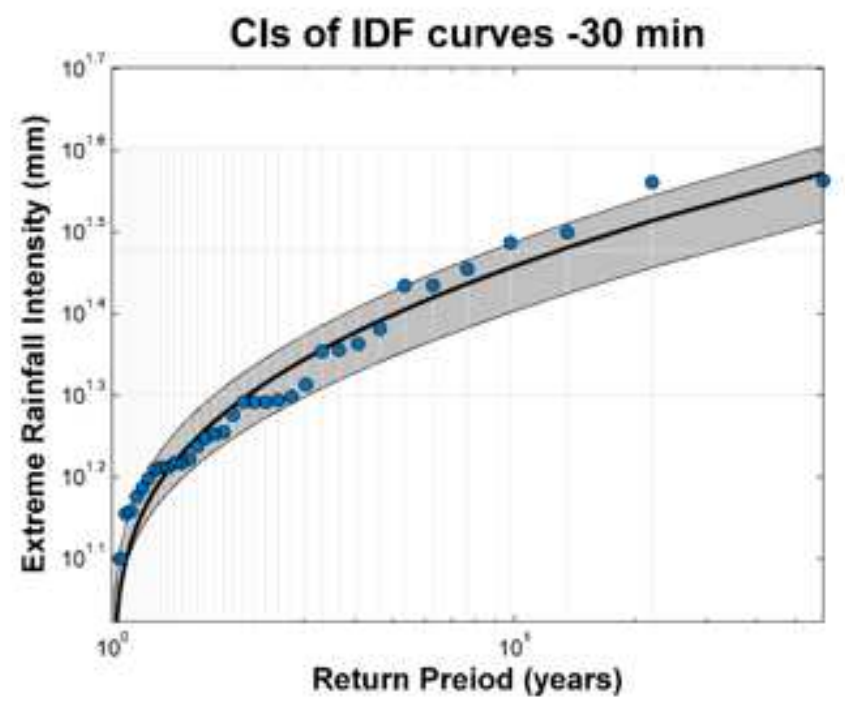

(B)

Figure 10

The $95 \%$ confidence intervals (Cls) of (A) IDF curves for the 5-min duration and (B) 30-min duration for Ottawa rain gauge station, respectively. Grey shade regions are the $90 \%$ Cls constructed by SDExtreme, black lines are the estimated IDF curves, and blue dots represent observed values. 


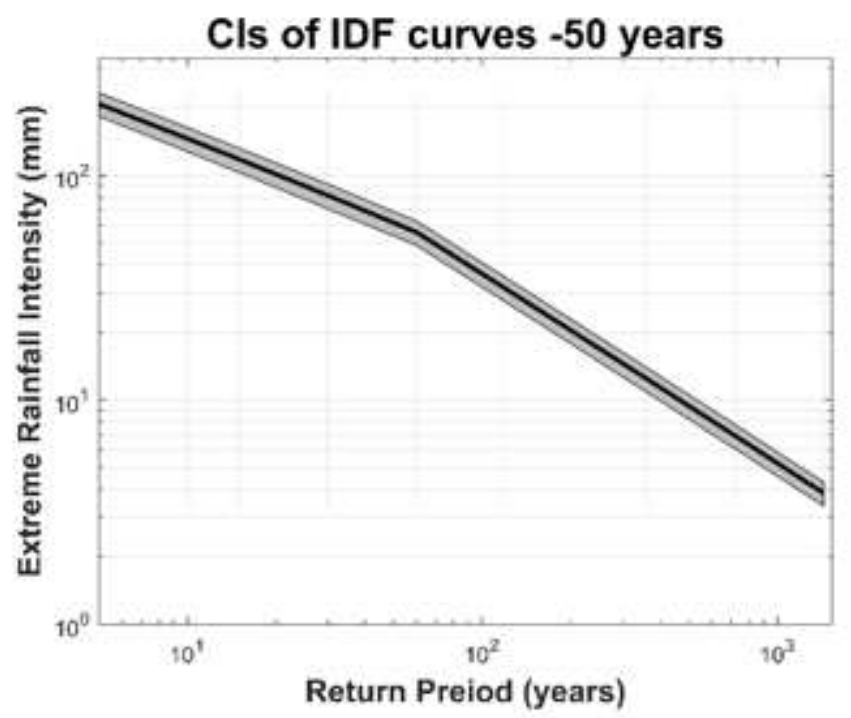

(A)

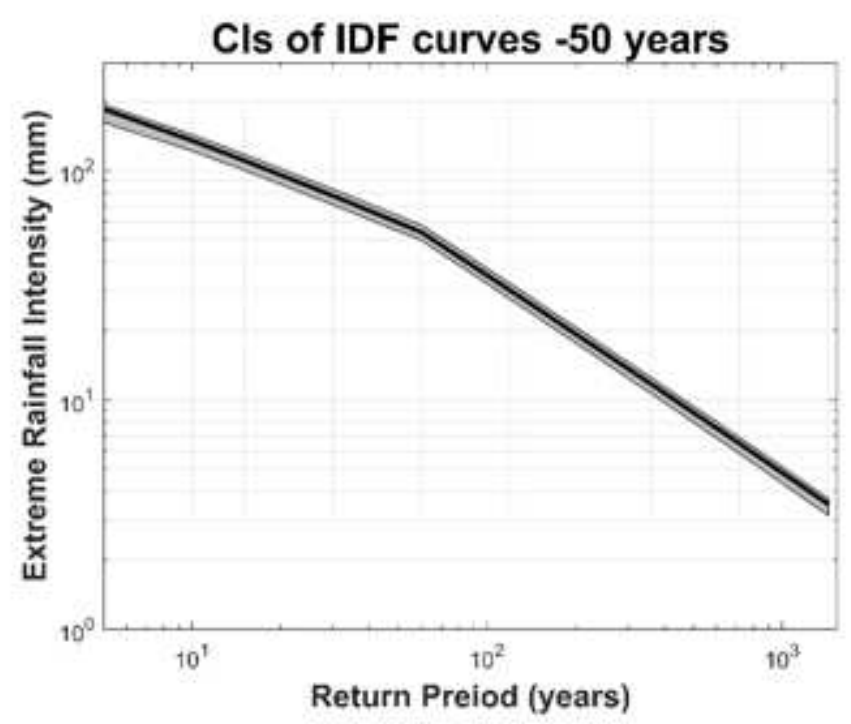

(C)

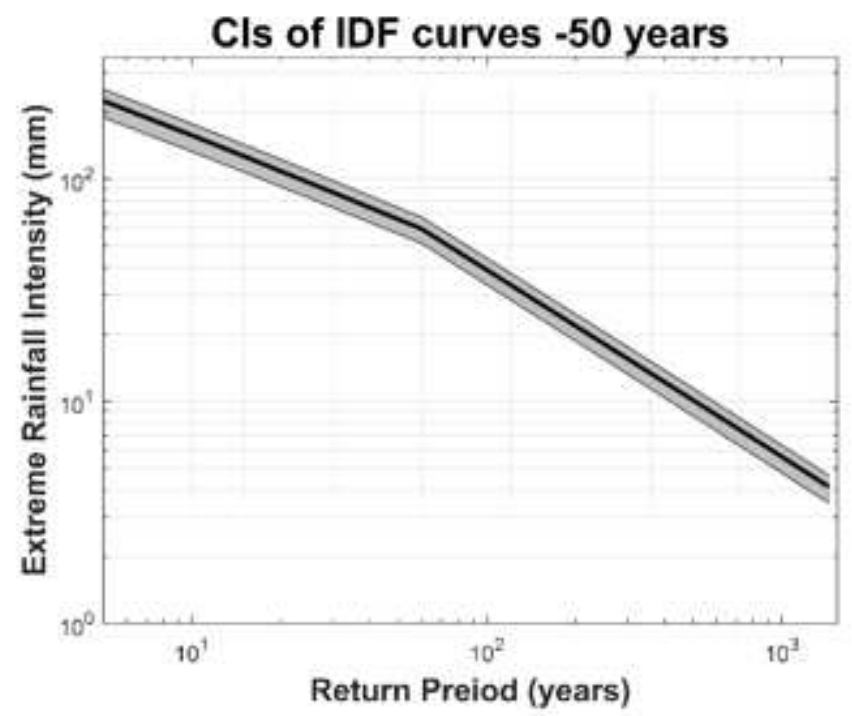

(B)

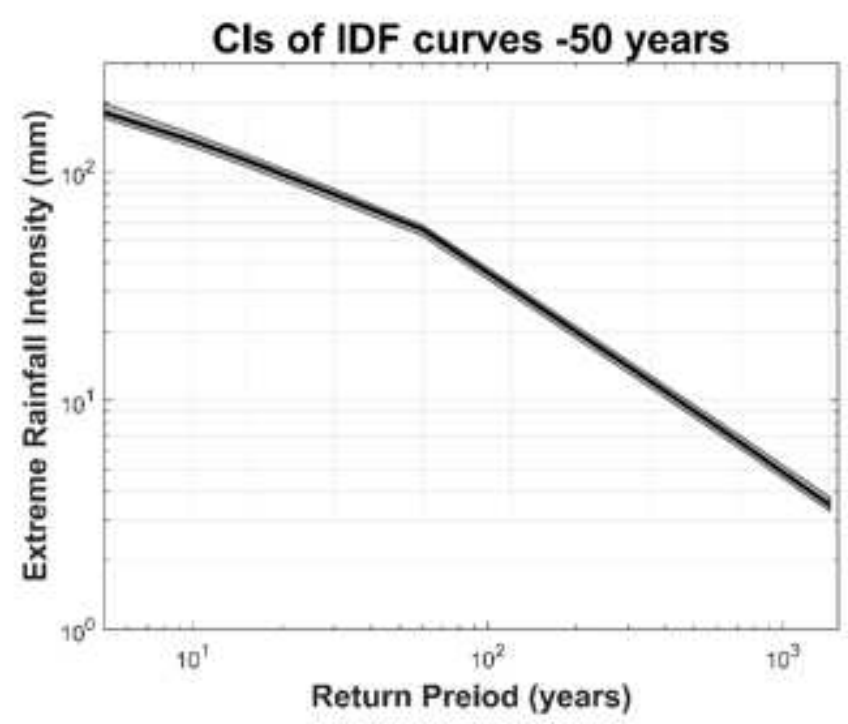

(D)

\section{Figure 11}

The $95 \%$ confidence intervals (Cls) for IDF curves (for the period of 2080s) corresponding to 50-year return periods estimated under two greenhouse gases emission scenarios (RCP 4.5, and RCP 8.5) given by CanESM2 and two (RCP 4.5 and RCP 8.5) by CanRCM4, respectively. (A) under RCP 4.5 by CanESM2, (B) under RCP 5.5 by CanESM2, and (C) under RCP 4.5 by CanRCM4, and (D) under RCP 8.5 by CanRCM4. Grey shade regions are the $95 \% \mathrm{Cls}$ and black lines are the estimated IDF curves by SDExtreme. 